\title{
Comparison of past and future Mediterranean high and low extremes of precipitation and river flow projected using different statistical downscaling methods
}

\author{
P. Quintana-Seguí ${ }^{1,2}$, F. Habets ${ }^{3}$, and E. Martin ${ }^{2}$ \\ ${ }^{1}$ Observatori de l'Ebre (OE), CSIC - Universitat Ramon Llull, Roquetes, Spain \\ ${ }^{2}$ CNRM-GAME, URA1357, CNRS - Météo-France, Toulouse, France \\ ${ }^{3}$ CNRS/UPMC, UMR7619 Sisyphe, Mines-Paristech, France
}

Received: 15 June 2010 - Revised: 1 April 2011 - Accepted: 25 April 2011 - Published: 16 May 2011

\begin{abstract}
The extremes of precipitation and river flow obtained using three different statistical downscaling methods applied to the same regional climate simulation have been compared. The methods compared are the anomaly method, quantile mapping and a weather typing. The hydrological model used in the study is distributed and it is applied to the Mediterranean basins of France. The study shows that both quantile mapping and weather typing methods are able to reproduce the high and low precipitation extremes in the region of interest. The study also shows that when the hydrological model is forced with these downscaled data, there are important differences in the outputs. This shows that the model amplifies the differences and that the downscaling of other atmospheric variables might be very relevant when simulating river discharges. In terms of river flow, the method of the anomalies, which is very simple, performs better than expected. The methods produce qualitatively similar future scenarios of the extremes of river flow. However, quantitatively, there are still significant differences between them for each individual gauging station. According to these scenarios, it is expected that in the middle of the 21 st century (2035-2064), the monthly low flows will have diminished almost everywhere in the region of our study by as much as $20 \%$. Regarding high flows, there will be important increases in the area of the Cévennes, which is already seriously affected by flash-floods. For some gauging stations in this area, the frequency of what was a 10-yr return flood at the end of the 20th century is expected to increase, with such return floods then occurring every two years in the middle
\end{abstract}

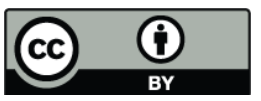

Correspondence to: P. Quintana-Seguí (pquintana@obsebre.es) of the 21 st century. Similarly, the 10 -yr return floods at that time are expected to carry $100 \%$ more water than the 10 -yr return floods experienced at the end of the 20th century. In the northern part of the Rhône basin, these extremes will be reduced.

\section{Introduction}

Climate Change represents an important challenge for our society as it obliges us to adapt our actions to a not wellknown future climate. This is especially true for high and low extremes of river flow, which have a strong impact on our lives. Their future changes must be taken into account, in order to correctly manage our limited water resources and also in order to correctly assess risks associated with the future hydrological cycle. However, unfortunately, the impact of climate change on these hydrological extremes is difficult to assess.

Global Climate Models (GCM) are the main tools available to study the future of the Earth's climate with, but their spatial resolution is too coarse to reproduce local characteristics of the climate system, such as topography, clouds or the sea breeze (Fowler et al., 2007; Planton et al., 2008). The solution to this problem is to downscale the GCM simulations to a higher resolution better adapted to the study of regional and local phenomena. The available techniques are not simple, though. In fact, the problem of downscaling is still very challenging, especially with spatially heterogeneous variables such as precipitation (Maraun et al., 2010).

Several methods exist to downscale and/or unbias the output of GCM simulations. These methods generally fit into two categories:

Published by Copernicus Publications on behalf of the European Geosciences Union. 
1. Dynamical downscaling: this approach consists of making a high-resolution simulation, which only simulates the processes of atmospheric and continental surfaces over the region of study, forced by a GCM at the boundaries. The models used in this context are called regional climate models (RCM) (Giorgi, 1990; Frei et al., 2003; Gibelin and Déqué, 2003).

2. Statistical downscaling: there are many and very different statistical approaches to downscaling. The main approach generally consists of linking a large-scale predictor from the GCM to a fine-scale variable (von Storch, 1995, 1999). It is even possible to directly develop a statistical relationship between large-scale variables from a GCM, and river flow (Tisseuil et al., 2010). Weather generators (Dubrovský et al., 2004) are also often used.

Dynamical downscaling is more costly in terms of computer resources but it is physically based, in contrast to statistical downscaling. Nevertheless, these two techniques are not incompatible. In fact, as the resolution of RCMs is still too coarse for most applications and these simulations are often biased, it is still necessary to downscale and unbias RCM data to force an impact model (Déqué, 2007). Statistical downscaling techniques are built upon the assumption that the corrections derived under the current climate will hold in a future and changed climate. This assumption is strong and probably it is not fully valid, therefore the different techniques might introduce artifacts which might be amplified by the impact model, increasing the uncertainty. Furthermore, the increase in resolution might misleadingly increase the confidence in the projections (Wilby et al., 2004). One could argue that it is not worth introducing this uncertainty and that, to study the anomalies of river discharge introduced by climate change, it would be enough to force the impact model directly with the RCM. Nevertheless, RCMs do not take into account the heterogeneity of the relief at the small scale, nor are able to reproduce small scale systems which are often the cause of the extremes of river flow. Lacking these features, these simulations cannot be used without further treatment.

A future warmer climate will enhance the hydrological cycle due to a higher water content in the atmosphere (Trenberth et al., 2003), which may lead to more frequent or more intense extremes of precipitation. In Europe, the PRUDENCE and ENSEMBLE projects (Beniston et al., 2007; Boberg et al., 2009; Frei et al., 2006) confirmed such behaviour using several RCMs. Although the results show a large uncertainty associated with the choice of the GCM, the trend in the extremes of precipitation is consistent and greater than the one on the mean (Planton et al., 2008). Studies into the impact of climate change on river flow extremes are not numerous and most of them do not take into account the impact of the methods of downscaling and unbiasing (Prudhomme et al., 2002 is an exception). Lehner et al. (2006) used the monthly outputs of two GCM at $0.5^{\circ}$ of resolution, assuming no change in the duration of wet or dry spells. Cunderlik and Simonovic (2005) used a weather generator that carries out annual re-sampling. Raff et al. (2009) also used a weather generator to downscale monthly output from GCM simulations. Prudhomme et al. (2003) showed the large sensitivity of floods to the choice of the GCM. Dankers and Feyen (2009) used RCM simulations from the PRUDENCE project, without bias correction, to assess the impact of climate change on floods and droughts in Europe. Prudhomme et al. (2002) studied the impact of three downscaling methods in the simulation of floods on a small catchment area in the UK. They used a perturbation method and tested 3 different versions by modifying the wet spells, showing an important impact on flood frequency and intensity. It is expected that such a method would also have a large impact on low flows.

The objective of this study is to evaluate the differences between the future scenarios of extremes of precipitation and river flow simulated using different downscaling methods.

The study is applied to the French Mediterranean area, which includes Mediterranean basins as well as some basins with a Mediterranean climate, even though they do not flow into the Mediterranean Sea. This area contains three contrasting regions: the mountainous Alps, where snow plays an important role, the North, which is rather humid, and the South, which is drier and where heavy precipitation events often lead to flash floods (Delrieu et al., 2005; Ducrocq et al., 2002). Thus, in this part of the basin, the ability of the downscaling method to reproduce heavy precipitation should have a direct impact on the estimation of floods. Regarding the low flow, one important issue is the ability of the downscaled method to reproduce the persistence of dry spells.

In this study, three downscaling methods are used, and applied to a single RCM simulation: the anomaly method, which is one of the most widely used in hydrological studies (Prudhomme et al., 2002), the quantile mapping approach (Déqué, 2007), which is an evolution of the anomaly method (instead of correcting the mean, each percentile of the distribution is corrected) and, finally, the weather typing method of Boé et al. (2006). The uncertainty associated with these downscaling methods regarding the impact of climate change on the mean temperature, precipitation, evapotranspiration, and river flow was studied in Quintana Seguí et al. (2010).

Quintana Seguí et al. (2010) showed that, for precipitation, these methods produce similar long-term annual averages, but there are important differences - mainly in the spatial patterns of the fields. As the hydrological model is a nonlinear system, the differences are amplified by this. Therefore, for some seasons and basins the methods do not agree in the sign of the future anomaly and where they do agree in the sign, the differences in amplitude of the anomaly can reach $30 \%$. In fact, the study showed that it is not possible to determine the intensity of the anomaly for a specific gauging station. Nevertheless, there are some patterns common to all three methods. For precipitation, it was shown that 


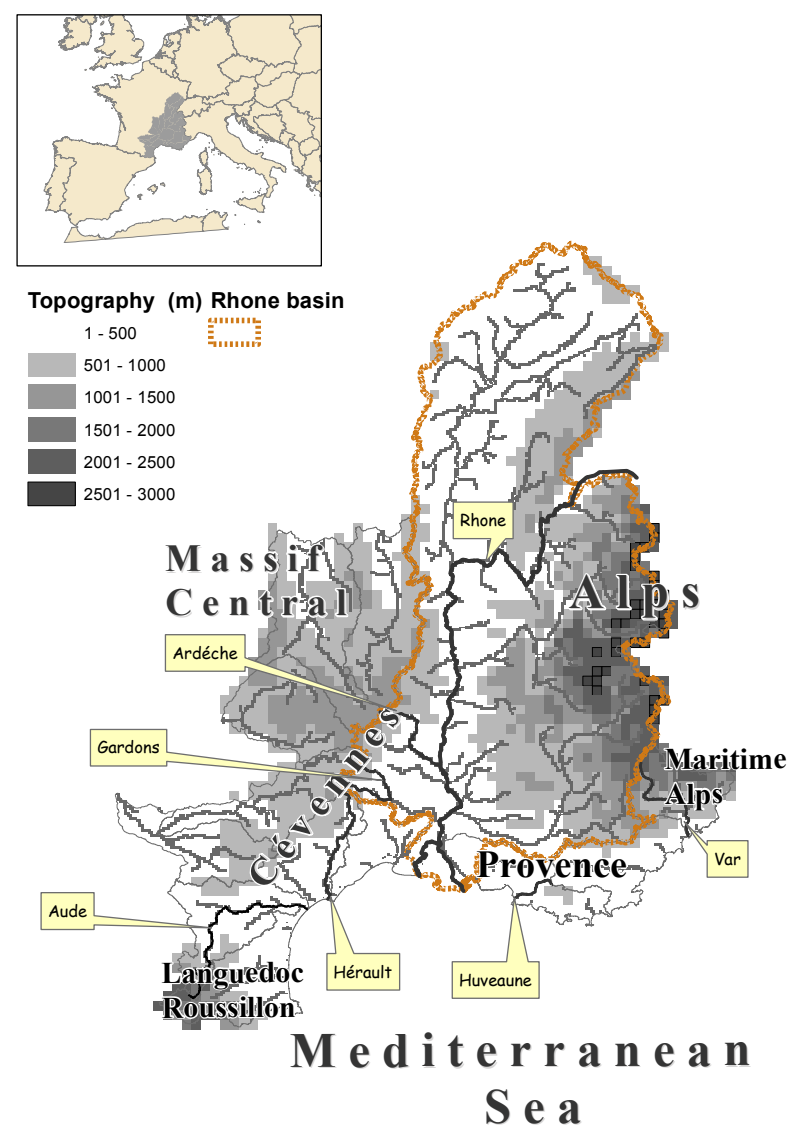

Fig. 1. Topographical map of the area of study. Featuring the Rhône basin and other Mediterranean basins of France.

significant decreases of summer precipitation are expected in the whole region for the middle of the 21st century and that, over the relief of the Cévennes (see Fig. 1), which is already prone to flash floods, a significant increase of mean precipitation is expected in winter. According to the study, these anomalies cause a decrease in the average discharge for most stations in the middle of the century, but it was also shown that for some stations situated on the relief of the Cévennes winter and maybe spring average flows might increase.

\section{Area of study}

As mentioned above, this study focuses on the French Mediterranean region (Fig. 1), which includes its Mediterranean basins as well as other basins which are climatically Mediterranean, mainly on the Massif Central. Four large cities are situated within this area: Montpellier, Marseille and Nice on the coast and Lyon in the northern half of the area. The coastal regions are densely populated. The increase of population in these areas increases the vulnerability of the human population to flash floods and droughts.

The largest French Mediterranean basin is the Rhône. Two of the main tributaries of the Rhône are Alpine and have a significant snow component. These tributaries are also heavily influenced by hydropower production. In our context, we are also interested in the small basins that are tributaries of the Rhône or flow into the Mediterranean sea and have a Mediterranean climate. To name a few: Aude, Hérault, Gardon, Ardèche, Huveaune and Var. These basins have sizes ranging from $373 \mathrm{~km}^{2}$ for the Huveaune up to $6074 \mathrm{~km}^{2}$ for the Aude and play a very important role in the the water supply for agriculture, industry and cities, as well as contributing freshwater to the sea. In some of these basins, there are some karstic systems which are difficult to model but are important for water supply.

The southern part of the area suffers from both high and low extremes of precipitation and, consequently, river flow. The reliefs of the Cévennes and the Alps can trigger strong precipitation events when they block the advance of mesoscale systems. For example, in September 2002, $700 \mathrm{~mm}$ were recorded in one day over the Gard basin (Delrieu et al., 2005). This caused severe catastrophic floods. Also, in summer, the southern part of the area of study is often affected by droughts: dry spells last two months and rivers can dry out. 


\section{Methodology}

This study was performed by downscaling a regional climate simulation. The climate simulation used was done with an Atmosphere-Ocean Regional Climate Model (AORCM). In order to downscale this simulate we used, as pseudoobservations, data from a gridded dataset of meteorological variables at screen level. The resulting downscaled data have a spatial resolution of $8 \mathrm{~km}$ and a temporal resolution of $1 \mathrm{~h}$. The resulting downscaled data were used to force a physically based and distributed hydrological model, which, for the control run, was also forced by the very same gridded dataset used for the downscaling. Afterwards, extreme indices of precipitation and river flow were calculated and analysed at the daily time scale.

\subsection{Climate simulation}

A single climate simulation was used in this study, which was performed using SAMM (Sea Atmosphere Mediterranean Model), developed by Somot et al. (2008). This is a coupling between the atmospheric model ARPEGEClimate (Gibelin and Déqué, 2003) and the model of the Mediterranean Sea OPAMED (Somot et al., 2006). SAMM is the first AORCM dedicated to the Mediterranean region. The maximum ARPEGE region for this area is of $50 \mathrm{~km}$, OPAMED's is about $10 \mathrm{~km}$. For the 21st century, the simulation was carried out using the IPCC SRES A2 scenario of emissions (Nakicenovic and Swart, 2000), which foresees high economic and demographic growth. The simulation covers a period of $139 \mathrm{yr}$ : from 1961 to 2099.

\subsection{Gridded database of observation}

A gridded database of meteorological observations at screen level (SAFRAN/F) was used to (1) force the hydrological model with observational data and (2) downscale the climate simulation to the resolution of the hydrological model. SAFRAN (Durand et al., 1993) is a meteorological analysis system that produces hourly analyses of near-surface atmospheric parameters at a spatial resolution of $8 \mathrm{~km}$ using observations from the automatic, synoptic and climatological networks of Météo-France and a first guess from a large-scale operational weather prediction model. The observations are analysed every $6 \mathrm{~h}$ for most variables and every day for precipitation. Then the analysis is interpolated to the hourly scale. SAFRAN uses optimal interpolation to do the analysis. However, due to the lack of radiation data, incoming solar radiation and downward infrared radiation are simulated using a radiative transfer scheme (Ritter and Geleyn, 1992). SAFRAN/F is the implementation of SAFRAN over mainland France. A more detailed description of SAFRAN/F is found in Quintana-Seguí et al. (2008) and Vidal et al. (2010). In this paper SAFRAN/F will also be referred to as SF.

\subsection{Methods of downscaling}

The description of the methods of downscaling used in this study will be short, as these same methods are explained in detail in Quintana Seguí et al. (2010). The three methods used belong to the statistical downscaling type. However, as these methods are applied to an AORCM, the methodology also involves a dynamical downscaling. The methods of statistical downscaling are used both to correct the bias of the RCM and to increase its the resolution. In all cases, the AORCM simulation is downscaled using the gridded database SAFRAN/F as a reference. Therefore, the resulting downscaled data have the same spatial and temporal resolutions as SAFRAN/F. All the methods assume that the corrections derived in the present climate will also be valid in the future, which is a strong assumption.

\subsubsection{Anomaly}

The anomalies method (AN) (which is also known as deltachange, alteration or perturbation method) (Caballero et al., 2007; Prudhomme et al., 2002) is the simplest one. It involves obtaining, from the climate simulation, a factor of climate change (the anomaly) and applying it to an observed series of data. In this case, the factor used is multiplicative $\left(\langle x\rangle_{\text {future }}=r \cdot\langle x\rangle_{\text {past }}\right)$. The correction is calculated monthly and for each SAFRAN grid cell as in Quintana Seguí et al. (2010). This method is very simple and convenient, therefore, it is widely used in the literature. However, it fails to take into account the changes in climate variability, which might be important for hydrological studies as shown by Prudhomme et al. (2002).

\subsubsection{Quantile mapping}

The quantile mapping technique (QM), which belongs to the regression models, as referred to in Fowler et al. (2007), consists of correcting the distribution function of the model. In this case, for each of the $8 \mathrm{~km}$ grid points, the time series of SAFRAN/F and the model (at the nearest grid point) are compared. Then, the distribution of the model is corrected for each percentile. Therefore, it is considered that the model rightly simulates to which percentile each value of the corrected variable belongs, nevertheless it is not able to determine the value associated to each percentile. Corrections calculated by this method include the systematic biases due to the dynamics and physics of the model. The correction is applied to each variable separately.

\subsubsection{Weather typing}

The weather typing (WT) approach used in this study is an extension to all of mainland France (Pagé et al., 2008; Boé, 2007; Boé et al., 2009) of the method initially developed for the Seine basin and described by Boé et al. (2006). This method is based on weather typing and conditional 
resampling. Two large-scale predictors are used: sea level pressure (SLP) and surface temperature. First, a limited number of weather types discriminating for precipitation in France are extracted as in Boé and Terray (2008). Each season is processed independently and between 8 and 9 weather types are obtained. Then each day $D$ of a climate projection is downscaled in accordance with its SLP and surface temperature. In the learning, period a day $D^{\prime}$ belonging to the same weather type as day $D$ with the most similar precipitation indices and temperature is selected. The method has been developed to be applied to the whole of France, not only to the Southeast. Therefore, the results in this region are not optimal, as its climate has some particularities in comparison with the rest of the country (it is more variable, drier in summer, etc.).

\subsection{Hydrological model}

The hydrological simulations performed in this study were carried out with the SIM model, which simulates energy and water balances and their associated river discharges over all of France, (Habets et al., 2008; Quintana Seguí et al., 2009). The soil-vegetation-atmosphere transfer scheme ISBA (Noilhan and Mahfouf, 1996; Noilhan and Planton, 1989; Boone et al., 1999) is the core of the system. ISBA calculates all the energy and water fluxes between the Earth's surface and the atmosphere. The version of ISBA used in this study includes an exponential profile of hydraulic conductivity, as described in Decharme et al. (2006) and Quintana Seguí et al. (2009). ISBA is coupled with the hydro-geological model MODCOU (Ledoux et al., 1989) through the surface and subsurface runoff. MODCOU routes these two fluxes to the river and within the river. Modcou also simulates the underground water in the Seine and Rhône basins. The resolution of ISBA is $8 \mathrm{~km}$. The spatial resolution of MODCOU is variable. MODCOU calculates river discharges over more than 900 points. In this study, daily discharges were used. The whole system is forced by the SAFRAN/F database, as described in Sect. 3.2, or by the data obtained from applying downscaling techniques to climate simulations, as described in Sect. 3.3.

SIM is a mostly physically based large-scale model (it simulates all of mainland France). This allows us to study a great number of basins under the same conditions, avoiding most of the calibration needed with other models. Most of the parameters are derived from a physiographical database (Masson et al., 2003). Some parameters were calibrated using a simple procedure (Quintana Seguí et al., 2009).

However, the model also has some disadvantages: SIM does not excel in reproducing the extremes of river flow (Sauquet and Leblois, 2001; Habets et al., 2008). For high flows, it offers a more accurate reproduction for flows over scales of several days than for daily scale flows (which are studied in this article), and it has some difficulties with flash floods, which are significant in some basins of the area of
Table 1. Hydrological simulations run for this study.

\begin{tabular}{|c|c|c|c|}
\hline Simulation & $\begin{array}{l}\text { Atmospheric } \\
\text { data }\end{array}$ & $\begin{array}{l}\text { Downscaling } \\
\text { method }\end{array}$ & $\begin{array}{l}\text { Period } \\
\text { covered }\end{array}$ \\
\hline SF & SAFRAN/F & None & 1970-1999 \\
\hline AN & SAMM & Anomaly & 2035-2064 \\
\hline QM & SAMM & Quantile Mapping & $\begin{array}{l}1970-1999 \\
\text { and 2035-2064 }\end{array}$ \\
\hline WT & SAMM & Weather Typing & $\begin{array}{l}1970-1999 \\
\text { and } 2035-2064\end{array}$ \\
\hline
\end{tabular}

study. This is partly linked to the use of a constant velocity to route the flow to the river and within the river. With low flows, the model has some difficulties. These are related to the lack of an explicit simulation of underground waters and their interaction with the river in most basins (the model only simulates the aquifers of the Rhône and the Seine). In fact, the model performs better in humid years than in dry ones (Habets et al., 2008), which might be a problem as the future is expected to be drier in this region (Quintana Seguí et al., 2010). An assessment of the model's ability to reproduce extreme flow is presented in Sect. 4.2.

\subsection{Hydrological simulations}

The previously described hydrological model was used to run three simulations over two periods of 30 yr: 1970-1999 and 2035-2064 (see Table 1). The control run (SF) was forced by SAFRAN/F. Obviously, this simulation only covers the first period. The other simulations were forced by the climate simulation (SAMM) and downscaled by the three downscaling methods described in Sect. 3.3. AN only covers the second period.

In this paper, instead of calendar years, hydrological years are used. These begin on 1 August. Thus the year 1970 covers the period from 1 August 1970 to 31 July 1971.

\subsection{Data of observed river flow}

The data of daily river flows used in this paper come from the French Banque Hydro ${ }^{1}$.

\subsection{Indices of extremes}

A set of indices was selected to represent the main features of precipitation and river discharge extremes.

\subsubsection{Indices of precipitation}

Table 2 sums up the indices used to describe the high and low extremes of precipitation. These indices are chosen from the list of indices used in the STARDEX project (Goodess,

\footnotetext{
${ }^{1}$ http://www.hydro.eaufrance.fr/
} 
Table 2. Indices of extremes of precipitation and temperature.

\begin{tabular}{|c|c|c|}
\hline Name & Description & Units \\
\hline \multicolumn{3}{|c|}{ Precipitation } \\
\hline PQ90 & 90th percentile of rainday amounts & $\mathrm{mmd}^{-1}$ \\
\hline PQ95 & 95th percentile of rainday amounts & $\mathrm{mmd}^{-1}$ \\
\hline PF90 & Fraction of total precipitation above annual 90th percentile & \\
\hline PF95 & Fraction of total precipitation above annual 95th percentile & \\
\hline PDJJA & Driest summer & mmsummer $^{-1}$ \\
\hline PXCDD & Max no. consecutive dry days & $\mathrm{d}$ \\
\hline \multicolumn{3}{|c|}{ River Flow } \\
\hline QJXA10 & Annual daily maximum with a mean return period of $10 \mathrm{yr}$ & $\mathrm{mmd}^{-1}$ \\
\hline QMNA5 & Annual monthly minimum with a mean return period of $5 \mathrm{yr}$ & $\mathrm{mmm}^{-1}$ \\
\hline
\end{tabular}

2003), except the "driest summer". The first four indices are aimed at describing heavy precipitation. This is especially important in the Mediterranean region of France, because the events of very intense precipitation and their associated flashfloods are not rare. PQ90 and PQ95 are indicators of the intensity of strong precipitation events. PF90 and PF95 are indicators of the regime of precipitation: if these increase, the precipitation is more concentrated in fewer intense events, making water use more difficult for both vegetation and humans.

The region is also vulnerable to drought, especially in summer and near the coast, where the population density is highest. Therefore two indices of low precipitatio were also introduced. PDJJA is the driest summer (defined by the months JJA) and PXCDD is the longest persistence of dry days (i.e. days with less than $1 \mathrm{mmd}^{-1}$ of precipitation).

\subsubsection{Indices of river flow}

Table 2 also mentions the two indices of river flow that were selected: one for high flows and another one for low flows. Both indices are based on classical frequency analysis and are used by the French water agencies.

1. High flows: the annual daily maximum with a mean return period of $10 \mathrm{yr}$ was chosen. This index, which we call QJXA10, as it is known in France, is the equivalent of the Q10 in the USA. It was calculated assuming that the annual extremes follow a Gumbel distribution.

2. Low flows: the annual monthly minimum with a mean return period of $5 \mathrm{yr}$ (QMNA5 in France, 30Q5 in the USA) was chosen, with the assumption that the annual extremes follow a lognormal distribution.

In both cases, the indices were deduced from both periods of $30 \mathrm{yr}$, assuming stationarity and over a selection of points corresponding to river gauging stations. The assumption of stationarity, which states that the distribution of the variable studied does not change in time, is difficult to assume in the context of climate change. Other methods that take into account the non-stationarity of a changing climate should be used (Strupczewski et al., 2001). Nevertheless, in this study, the indices are applied to two different and relatively short periods of $30 \mathrm{yr}$, separated in time by $35 \mathrm{yr}$. Even though these two periods do not strictly fulfil stationarity, they are more stationary than the whole period 1970-2064. Therefore, in a first approximation, it is possible to make this assumption and use these indices (Prudhomme et al., 2003). An important benefit in using these two indices is that they are standard and used by the French administration. Therefore, the results of the study can be readily compared to existing data.

\section{Results}

This study focuses on two variables: precipitation and river flow. First, we study how the extremes of precipitation produced by the downscaling methods compare to the observations (SAFRAN/F). Then, we study how the different projections of precipitation compare to the past (anomalies) and between themselves (differences between methods). Finally, we analyse how these differences are propagated to river flows, for both the present and the future.

\subsection{Precipitation}

\subsubsection{Comparison of downscaling methods and SAFRAN/F: 1970-1999}

Figure 2 shows the spatial distribution of PQ95 for the end of the 20th century. According to SAFRAN/F (SF), PQ95 is greater than $30 \mathrm{mmd}^{-1}$ for most of the region and it reaches more than $50 \mathrm{mmd}^{-1}$ on the Cévennes. The map of the RCM is very homogeneous. There is a very slight increase of this 


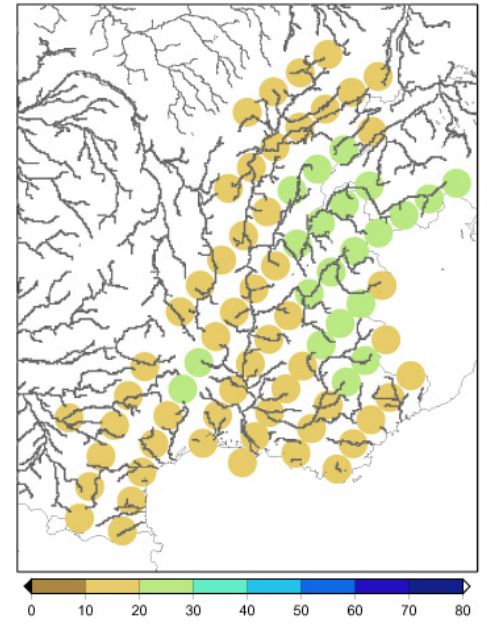

(a) SAMM 1970

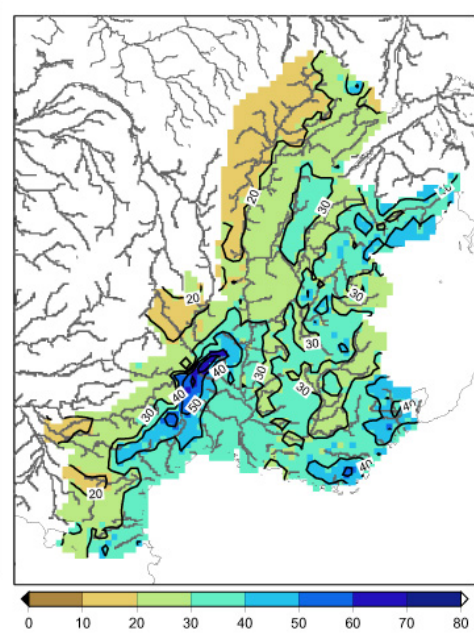

(b) SF 1970

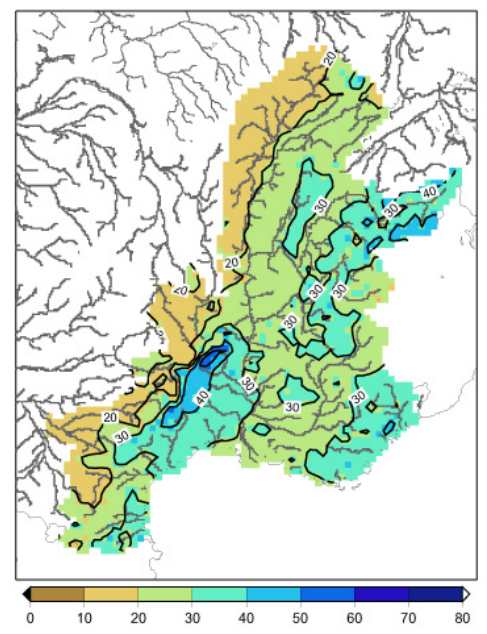

(c) WT 1970

Fig. 2. PQ95 (in mm day ${ }^{-1}$ ) as reproduced by SAMM, SAFRAN/F and WT for the period 1970-1999.

index on the Alps and in two grid cells over the Cévennes. This result illustrates the need to downscale the RCM. As expected, SF and QM produce the same fields, as by construction QM reproduces the same percentiles as SF. Therefore, this field is not shown. WT and SF reproduce similar patterns, but the extremes of WT are lighter than those of SF. On the Cévennes, WT is capable of reproducing zones of PQ95 greater than 40 and $50 \mathrm{mmd}^{-1}$, like SF, but the areas of intense PQ95 are smaller, as expected. Compared to the RCM, WT does a good job in correcting and downscaling the output of the model. Regarding PQ90 (not shown), the difference between WT and SF is important on the Cévennes. SF shows a zone of PQ90 greater than $30 \mathrm{mmd}^{-1}$ in this region, but WT is not able to reproduce this behaviour for this mountain range.

Over almost the whole region under study, according to SF, PF90 (not shown) is greater than $30 \%$ and it is greater than $40 \%$ in the southwestern part of the domain between the Cévennes and the coast. PF95 (Fig. 3) is greater than $20 \%$ in the southern two thirds of the domain and greater than $30 \%$ for some parts of the Cévennes and the Catalan coast (southwest). These areas are very prone to typical strong Mediterranean events and the variability of precipitation is high. SAMM is not able at all to reproduce this index, showing homogeneous low values all over the area. Both QM and WT produce patterns of PF90 very close to those of SF. For PF95, both WT and QM underestimate the area of PF95 $>30 \%$. It is worth noting that, in this case, QM and SF do not produce the same results, even though they are very close. Both QM and WT underestimate PF95 with the underestimation given by WT being greater than that of QM.

Figures 4 and 5 show the lower extremes of precipitation. Both QM and WT show a spatial structure of PDJJA very similar to that of SF, but they are both drier in the South and wetter in the Alps. On the other hand, the PXCDD fields (longest dry spell) are very different. In this case, WT is closer to SF, but remains very different. The QM field departs considerably from the others. In the QM method, the percentiles were calculated for rainy days. For a rainy day $P>0$. RCMs tend to drizzle too much (Gutowski et al., 2003), therefore QM tends to diminsih (dry up) the lower percentiles of precipitation. However, sometimes, the RCMs drizzle for the right reason, but QM does not know it. Therefore, QM tends to dry up the days of low precipitation extending the dry spells. Furthermore, to calculate the standard PXCDD, a day is considered dry if $P<1 \mathrm{~mm}$, which amplifies the effect. The ability of WT to correct the spells is noteworthy, even though it is far from perfect.

\subsubsection{Comparison of downscaling methods: 2035-2064}

After the comparison for the 20th century, the methods were compared for the middle of the 21 st century.

Figure 6 shows that SAMM produces anomalies that are not very relevant, being the most notable feature an increase of PQ95 on the Cévennes, towards the South, and on the northern extreme of the area. QM and WT are able to reproduce the general patterns provided by SAMM, but with more regional details. QM and WT produce increases of PQ95 percentile for most of the region, except the Alps. However, the patterns have notable differences. QM presents a centre of maximum increase $(+25 \%)$ for the southern part of the Cévennes, whereas for WT this pole is displaced to the south, to the border with Spain. WT presents another region with an strong increase of PQ95 situated in the northern part of the Cévennes, and also on the border with Italy, near the coast. It is expected that this will have effects on the changes of the high extremes of river flows, as the basins are not evenly 


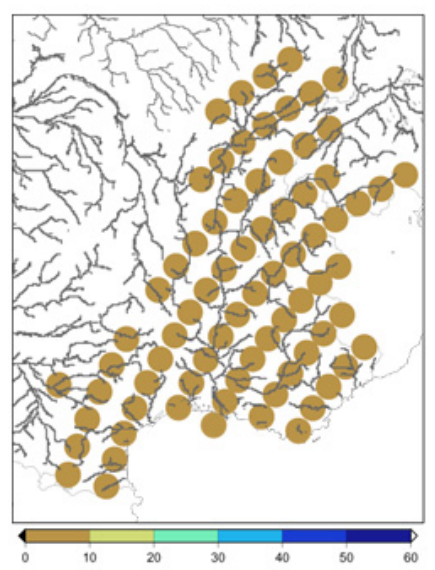

(a) SAMM 1970

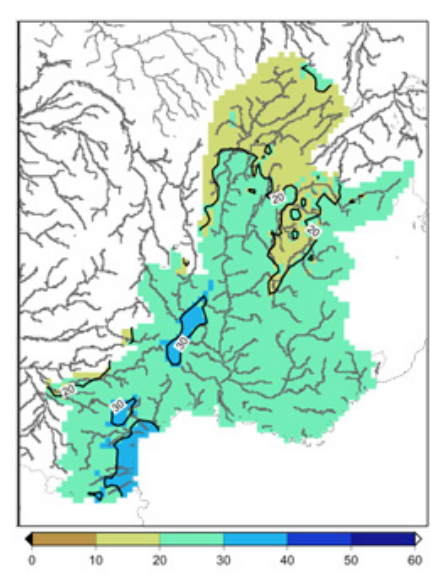

(b) SF 1970

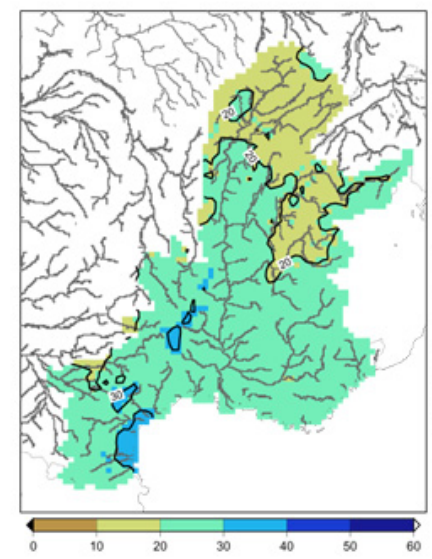

(c) QM 1970

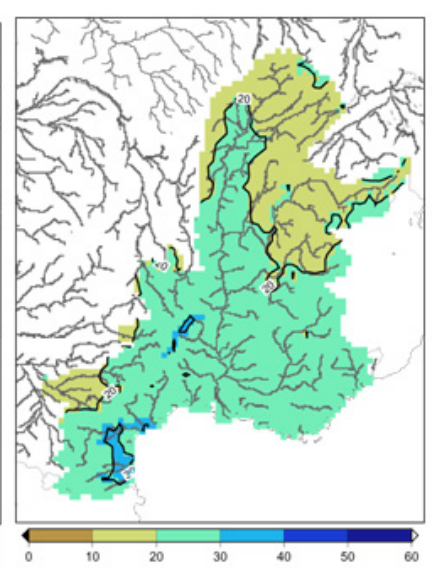

(d) WT 1970

Fig. 3. PF95 in the region of interest obtained from SAMM, SAFRAN/F and the downscaling methods for the period $1970-1999$.

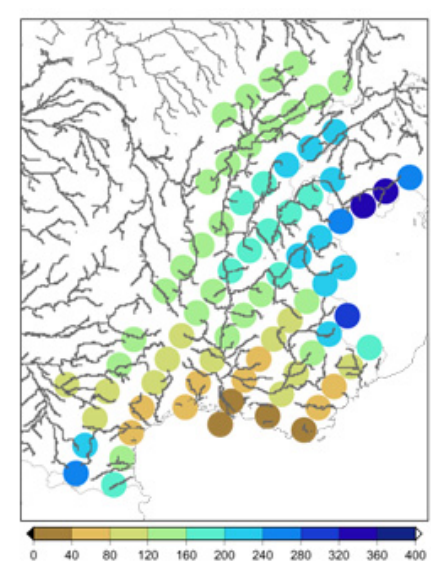

(a) SAMM 1970

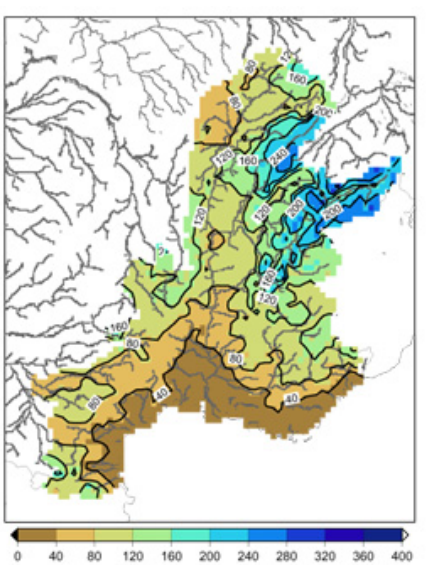

(b) SF 1970

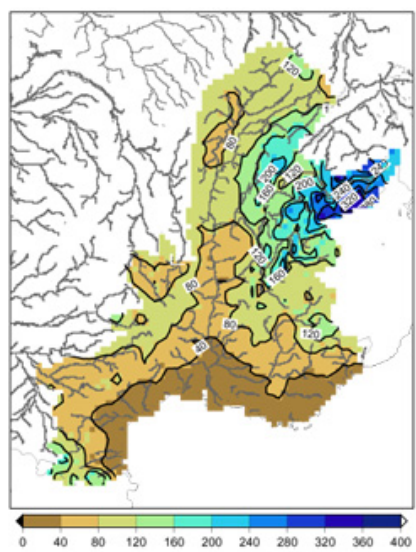

(c) QM 1970

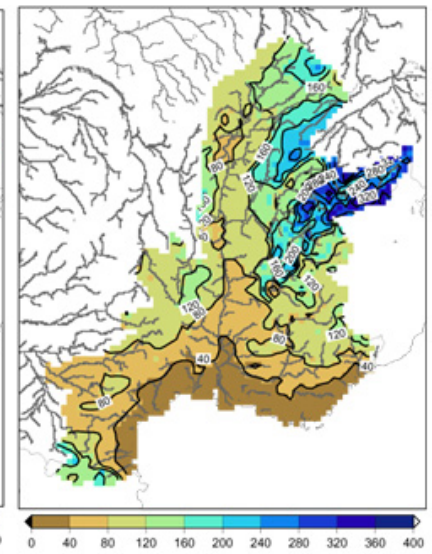

(d) WT 1970

Fig. 4. PDJJA in the region of interest obtained from SAMM, SAFRAN/F and the downscaling methods for the period 1970-1999.

affected (see Sect. 4.1). This figure also shows that $\mathrm{AN}$ is completely unable to reproduce this general increase of the percentile, as the method only modifies the mean and, therefore, shifts the whole distribution in the same way. As the mean is expected to decrease, so do the extremes. The patterns of change of PQ90 are not shown because they are very similar.

The anomalies of PF95 and PF90 (not shown) are not very important. According to QM and WT, they will be between 0 and +2 percentage points over most of the region and between +2 and +4 points in some areas of the southern part of the region of study. The exact patterns of change differ between methods. The only remarkable change is in QM. It shows an increase of +8 points for the southern part of the Cévennes, for both PF90 and PF95.

Figures 7 and 8 show the anomalies of the dry extremes. In both cases, the fields produced by the downscaling techniques are very different. As a consequence, the uncertainties are very high for these extremes. These uncertainties will probably be reflected by the hydrological model. In both cases, the patterns of QM are closer to those of SAMM. Regarding PDJJA, AN produces a very homogeneous anomaly. This was expected, as the whole series is shifted according to the change on the mean. The change is not completely homogeneous, because the threshold between dry and wet days is set to $1 \mathrm{~mm}$. QM produces a stronger negative anomaly for most of the domain, which reflects the anomaly of the AORCM. On the other hand, the WT field is very noisy. Regarding PXCDD, the anomalies for AN are almost zero over most of the domain, as expected. They are not zero everywhere because of the $1 \mathrm{~mm}$ threshold. Again, the anomalies of QM and WT are very noisy. 


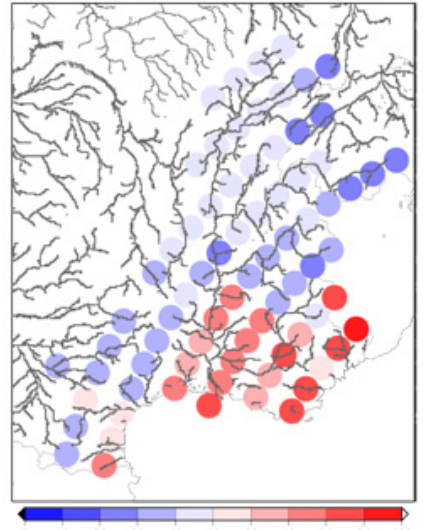

(a) SAMM 1970

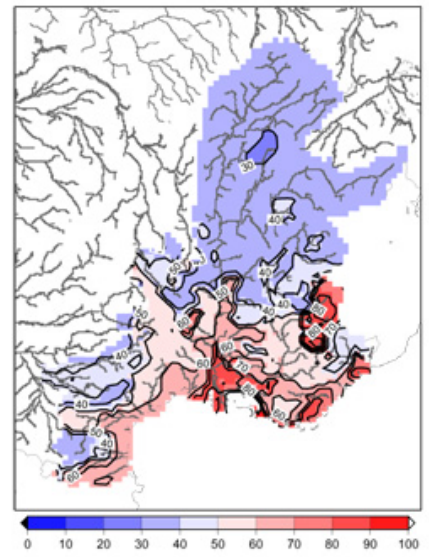

(b) SF 1970

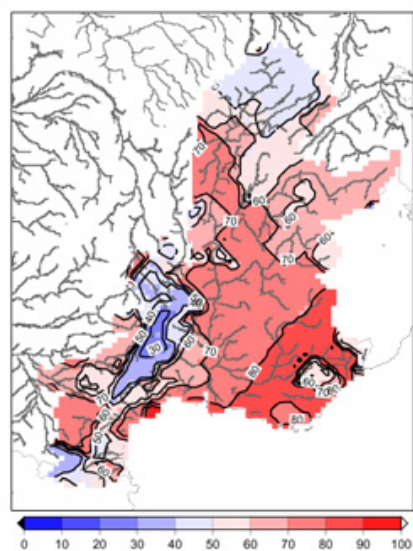

(c) QM 1970

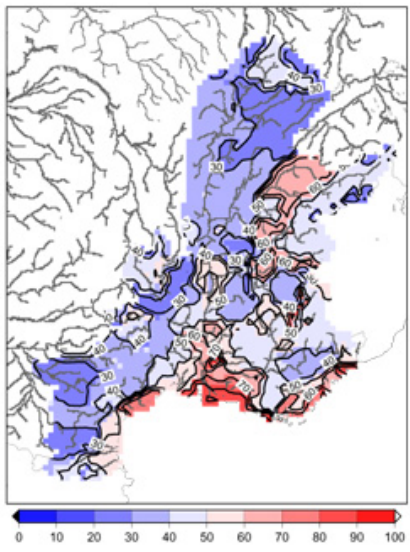

(d) WT 1970

Fig. 5. PXCDD in the region of interest obtained from SAMM, SAFRAN/F and the downscaling methods for the period $1970-1999$.

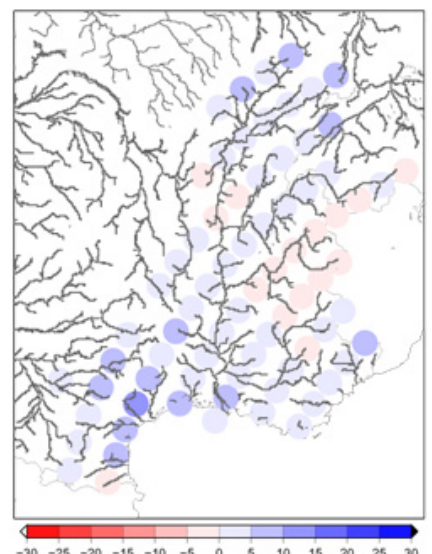

(a) SAMM

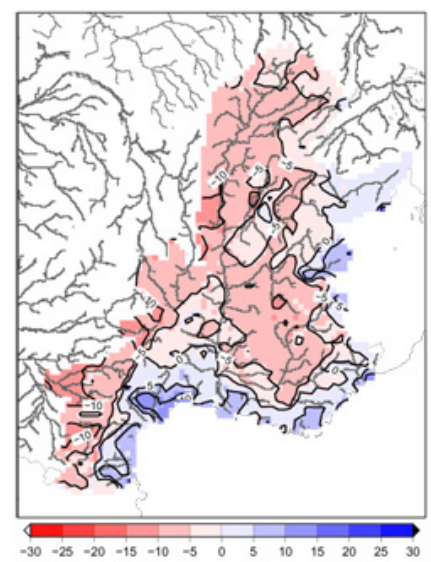

(b) $\mathrm{AN}$

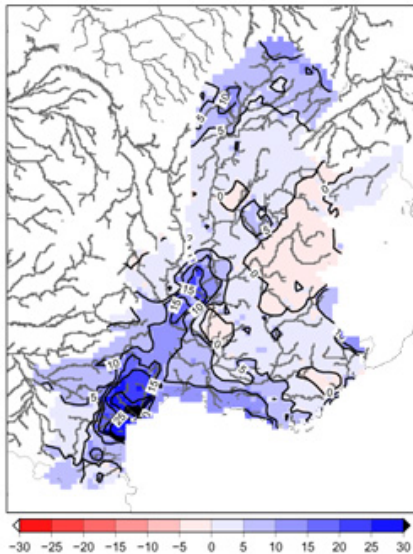

(c) QM

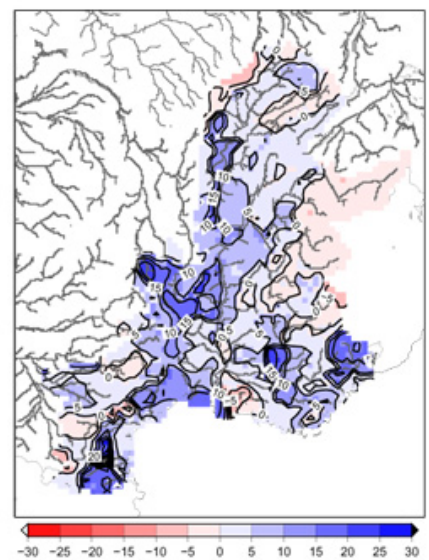

(d) WT

Fig. 6. Anomaly (2035-2064 vs. 1970-1999) of PQ95 (in \%).

\subsection{River flow}

In this section, we will study (1) how different the extremes of river flow are according to each statistical downscaling method and (2) how these differences are connected to the differences in the extremes of precipitation.

Section 4.1.1 showed that the extremes of precipitations from the RCM do not compare well to the reference (SAFRAN/F). Section 4.1.2 showed that the downscaled precipitation of QM and WT is, in most cases, able to keep the anomalies of the RCM, including the necessary local information. As the RCM is not able to reproduce the observed extremes of precipitation, we decided to study the impact of climate change on the extremes of the river flows using only the downscaled atmospheric forcing. Nonetheless, it would be also interesting to force the hydrological model directly with $\mathrm{RCM}$ data to see how the non realistic extremes of the RCM propagate throught the hydrological model. The simple anomaly method failed to reproduce the anomalies of the RCM on the extreme of precipitations; however, it is used on the following section as it has been extensively used in previous impact studies.

\subsubsection{Validation against observed discharge}

First, the ability of the model to simulate the observed extremes of river flow was studied.

Table A shows the gauging stations used to validate the performance of the model. The observed series of all these stations are, at least, $15 \mathrm{yr}$ long. The table also includes (see the last column) the Nash-Sutcliffe Efficiency (NSE; Nash and Sutcliffe, 1970) of the model for each station (using SAFRAN/F as atmospheric forcing), calculated over the whole hydrograph. The table is divided into two blocks, separated by a horizontal line, according to the NSE. Stations with an NSE greater than 0.5 were placed in the first group, 


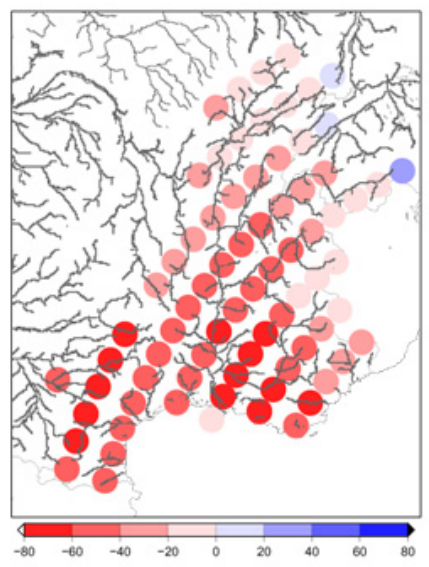

(a) SAMM

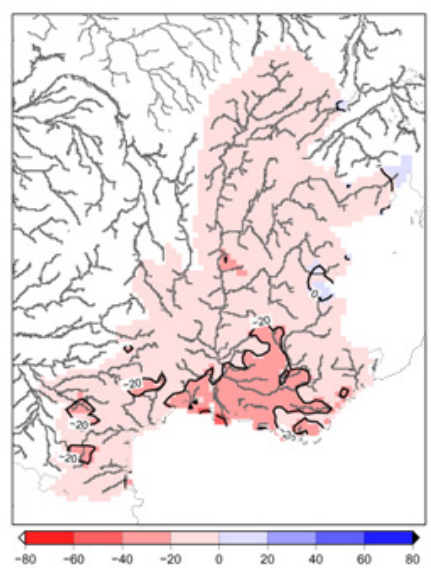

(b) $\mathrm{AN}$

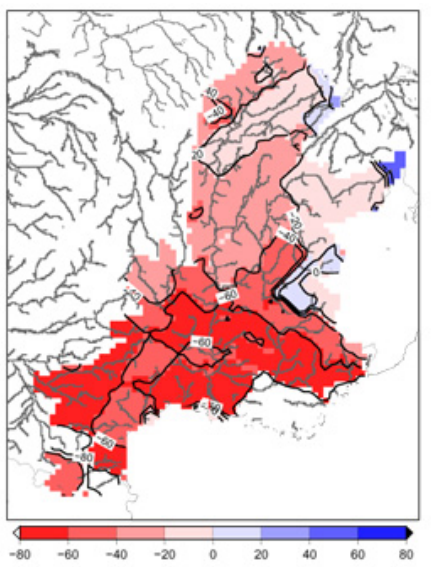

(c) QM

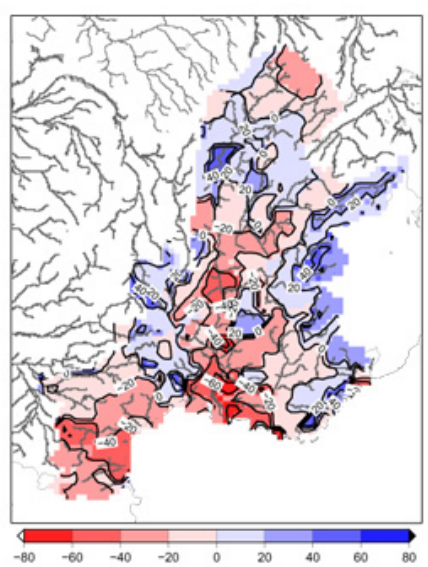

(d) WT

Fig. 7. Anomaly (2035-2064 vs. 1970-1999) of PDJJA (in \%).

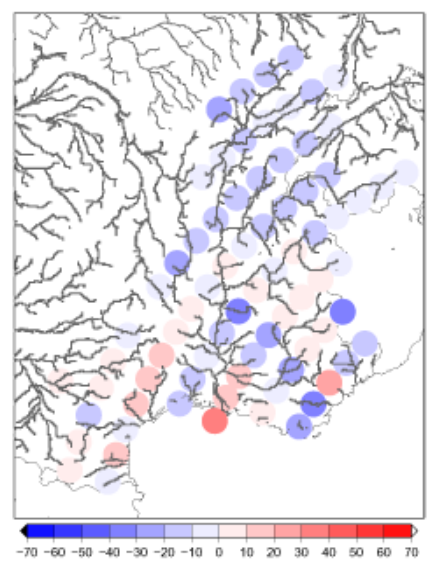

(a) SAMM

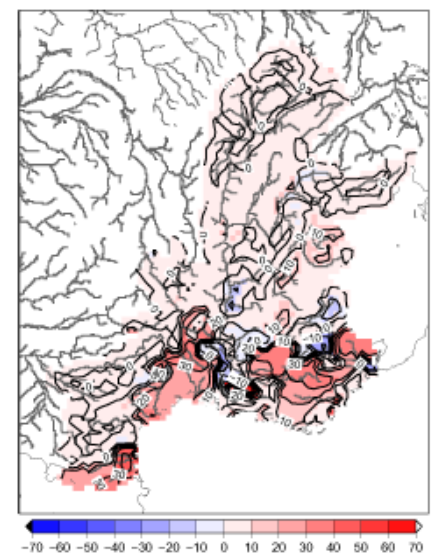

(b) $\mathrm{AN}$

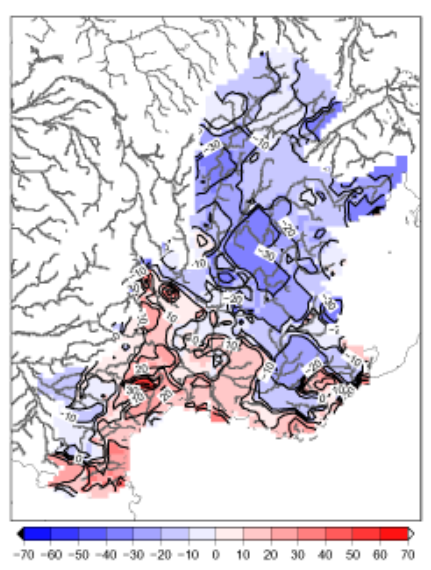

(c) QM

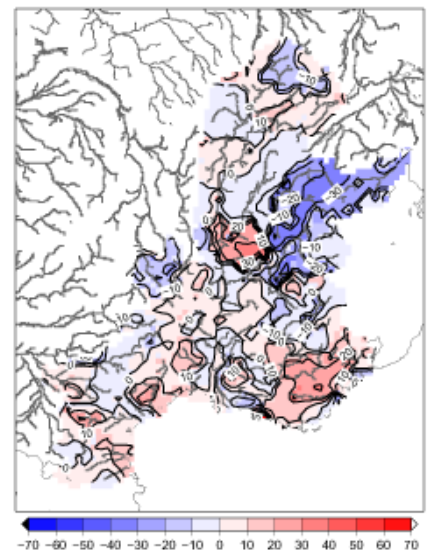

(d) WT

Fig. 8. Anomaly (2035-2064 vs. 1970-1999) of PXCDD (in days).

with the other ones going into the second group. The purpose of this division was to try to separate the stations where we know that the model works reasonably well from the rest of the stations. Of course, dividing the stations using an arbitrary NSE score is simplistic, but it helped us to interpret the results in the following sections. The causes of the bad performance of the model for the stations in the second group are diverse. There might be stations whose flows are severely affected by human influence or which belong to basins whith natural features that the model is not able to simulate (interaction with underground waters, which is not simulated for most of the stations, or the presence of karstic aquifers).

Figure 9 compares the observed and simulated QJXA10 and QMNA5, using SAFRAN/F as atmospheric forcing. The division intotwo groups (NSE $>0.5$ and the rest), presented in Table A is maintained. The 67 red dots of the figure represent stations where the model performs reasonably well according to the NSE (NSE $>=0.5$ ), while the 41 black dots represent the rest. The data was normalised for the surface of the basin (units in $\mathrm{mm}$ ) to avoid a false sense of goodness due to the difference in size of the basins. Table 3 shows the statistics related to the data depicted in Fig. 9. Two coefficients were calculated, the bias and the coefficient of determination $\left(R^{2}\right)$. The coefficient of determination is calculated as follows:

$$
R^{2}=1-\frac{\sum_{i}\left(o_{i}-m_{i}\right)^{2}}{\sum_{i}\left(o_{i}-\bar{o}\right)^{2}}
$$

where $o_{i}$ are the observed indices for each station $i$ and $m_{i}$ are the simulated ones. In fact, this coefficient is very similar to the NSE, but instead of applying it to a time series (the hydrograph), it is applied to the indices for each station (the data of Fig. 9). 


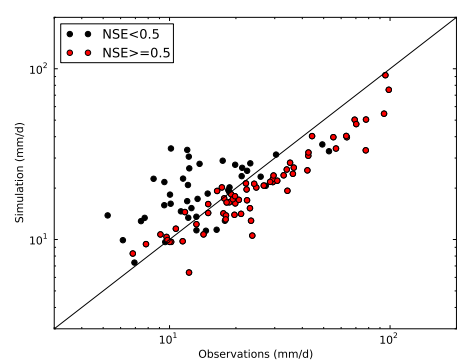

(a) SF QJXA10

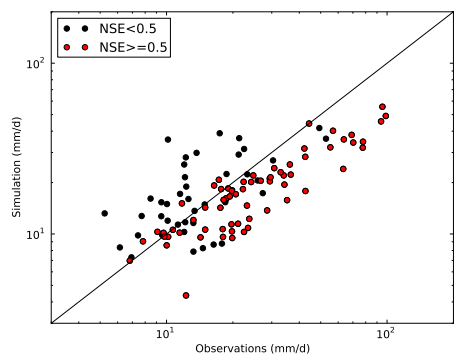

(c) QM QJXA10

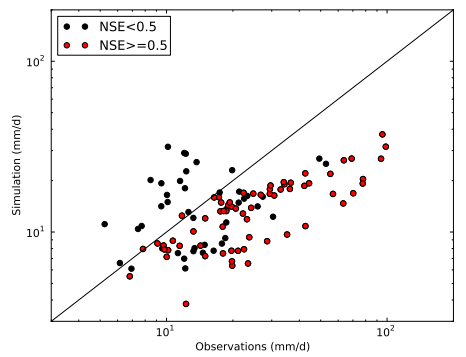

(e) WT QJXA10

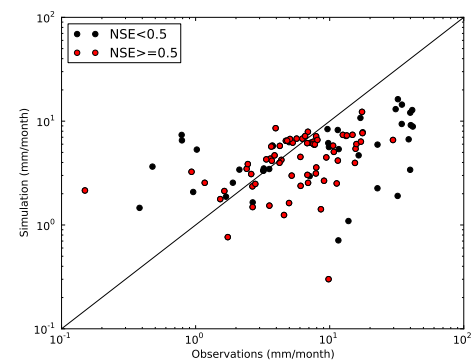

(b) SF QMNA5

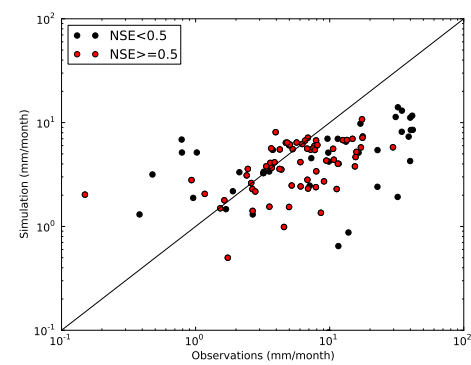

(d) QM QMNA5

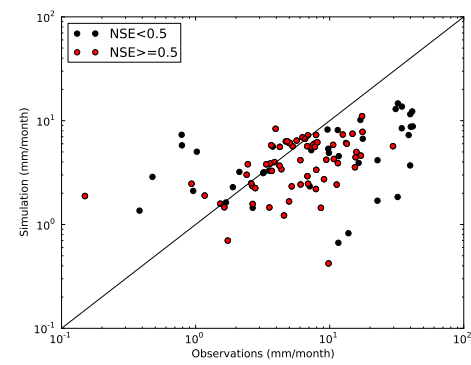

(f) WT QMNA5

Fig. 9. Comparison of the simulated (using SAFRAN/F as atmospheric forcing) and observed QJXA10 and QMNA5. Each dot corresponds to a gauging station. The calculations were made with stations with at least 15 full $\mathrm{yr}$ of observed data. Red dots represent the stations that the model simulates reasonably well (NSE $>0.5)$, black dots correspond to the rest.

Firstly, we analyse the SF simulation, which uses SAFRAN/F as atmospheric forcing. In panel (a) of Fig. 9, the red dots show that the model simulates the QJXA10 reasonably well for the stations where the model performs well (NSE $>0.5$ ), even though it tends to underestimate this index. Such results are comparable to those of Sauquet and Leblois (2001). This is partly linked to the fact that SAFRAN smooths strong local events and, also, to the simplicity of the routing scheme of MODCOU. Surprisingly, the bias is greater (in absolute terms) for the stations with better NSE. However, if we look at the figure, we will see that there is more dispersion in the black dots. These are stations where the model does not perform well. The cause of this performance might be regulation which tends to lower the extremes of high flow, thus causing an overestimation of these extremes. The negative bias of the stations where NSE $>0.5$ is not that surprising because SIM usually underestimates the peaks of flow. The $R^{2}$ is the same in both cases. This is also surprising, considering the distribution of the dots on the figure with the black ones being more dispersed. Panel (b) shows that the model simulates the QMNA5 worse than it simulates the QJXA10. In this case, the $R^{2}$ are 0 , which is a very bad score (the model is not better than a mean). For QMNA5, the NSE, which was used to split the data into two groups (red and black dots), might not discriminate well between good and bad stations. This is due to the fact that NSE is more sensitive to high flows. Also, the fact that the low flows are estimated using a subgrid drainage where the aquifers are not explicitly simulated must be taken into account. To sum up, when the model is forced by SAFRAN/F 


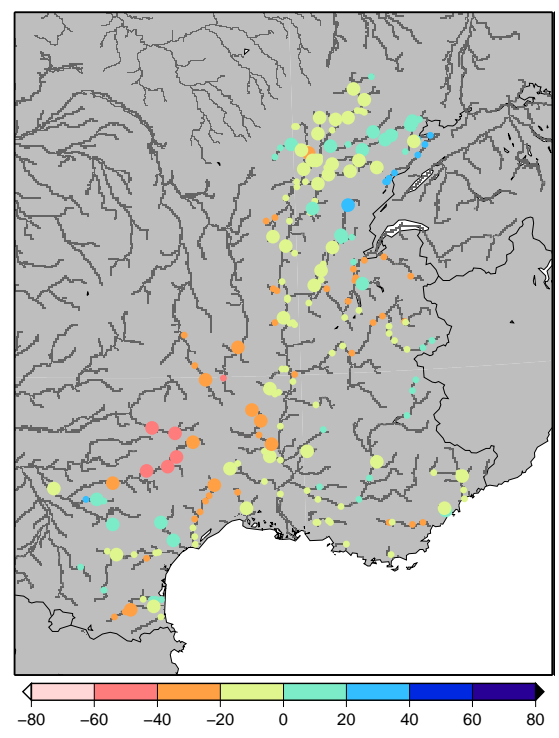

(a) QM

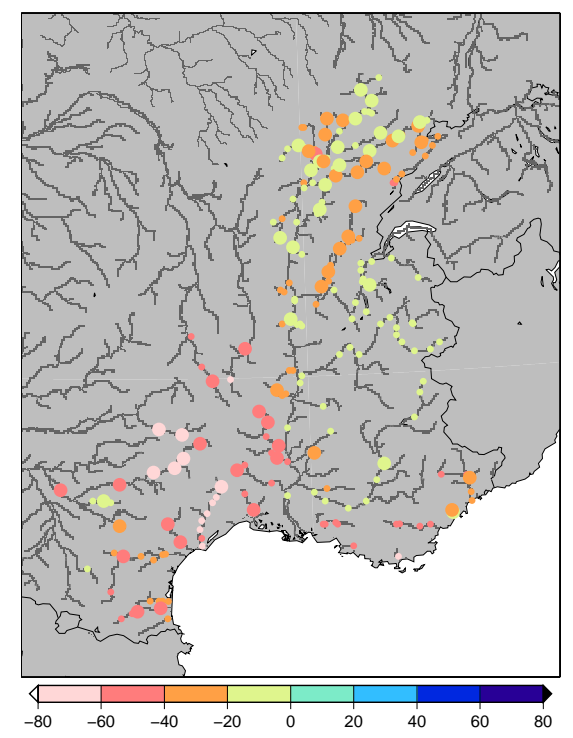

(b) WT

Fig. 10. Difference between the QJXA10 calculated with the two simulations forced by downscaling methods and the simulation forced by SAFRAN/F (in \%) for the period 1970-1999.

Table 3. Comparison between the simulations and the observations. The columns with normal font correspond to the stations that the model simulates reasonably well (NSE $>0.5$ ). The columns in italic correspond to the stations with a poor NSE (NSE $<0.5)$.

\begin{tabular}{lrrrr}
\hline & \multicolumn{4}{c}{ QJXA10 } \\
\cline { 2 - 5 } Simulation & \multicolumn{1}{c}{ Bias (\%) } & \multicolumn{2}{c}{$R^{2}$} \\
\hline SF & -18 & 7 & 0.7 & 0.7 \\
QM & -26 & 4 & 0.4 & 0.5 \\
WT & -44 & -22 & -0.2 & 0.0 \\
\hline & \multicolumn{4}{c}{ QMNA5 } \\
\cline { 2 - 5 } Simulation & \multicolumn{3}{c}{ Bias (\%) } & $R^{2}$ \\
\hline SF & 6 & 18 & 0.0 & 0.0 \\
QM & -3 & 7 & -0.1 & 0.0 \\
WT & -5 & 8 & -0.2 & 0.0 \\
\hline
\end{tabular}

it simulates the high flows of most stations reasonably well, even though it has a negative bias. On the other hand, the model has more difficulties in simulating the low flows. Therefore, in this study, we have more confidence in the results for QJXA10 than for QMNA5.

The next step is to compare the simulations forced by the downscaled climate model with the observations. Table 3 reveals that, for QJXA10, the scores remain acceptable for QM but that they are poor when the model is forced by WT. Regarding QMNA5, the model performs very similarly when it is forced by the pseudo-observations or by downscaled data.
The most surprising result of this comparison is the bad performance of WT. It was expected that both methods would underestimate the extremes, but it was not expected that the underestimation would be so significant, especially for WT. In this region, the 10-yr floods are directly connected to heavy precipitation events. Furthermore, as the PQ95 and PF95 are rather well estimated by WT and QM, except for the Cévennes, where WT has more difficulties, a better adequacy of the QJXA10 in this domain could be expected. But it must be taken into account that the 95th percentile is not extreme enough to directly deduce from it the behaviour of the QJXA10. Furthermore, this failure may be linked to a bad estimation of the other climatic variables apart from precipitation.

\subsubsection{Spatial comparison of the simulation: 1970-1999}

After comparing the simulations to the observations, we will now proceed to compare the simulations themselves.

Firstly, the simulations forced by QM and WT were compared to the simulation forced by SF. Figures 10 and 11 show the results for the simulated stations. The big dots correspond to the red stations of Fig. 9 (NSE $>=0.5$ ), the small dots represent the rest of stations:

1. Firstly, the figures show that the stations with NSE $>0.5$ do not cover the domain evenly. In fact, few of them are located on the Rhône river itself or in the Alpine region. The Alpine region is known to be very affected by water management, mainly for electricity production. Nevertheless, this influence is not the only cause of low 


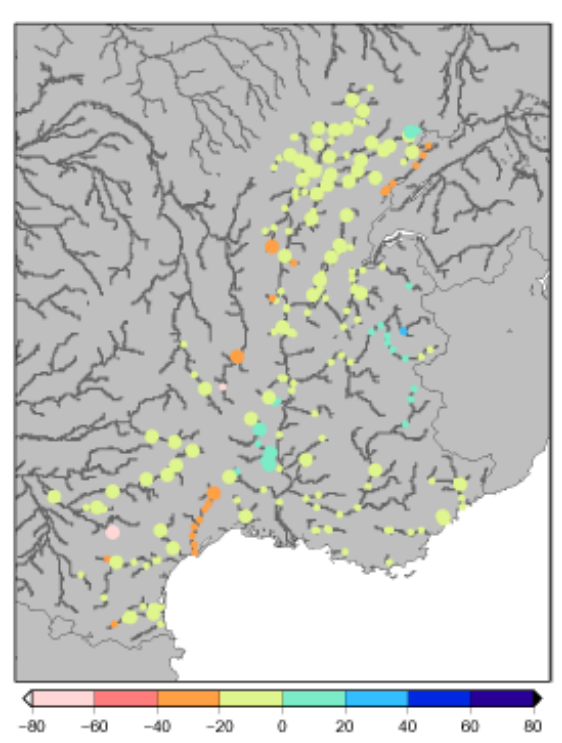

(a) QM

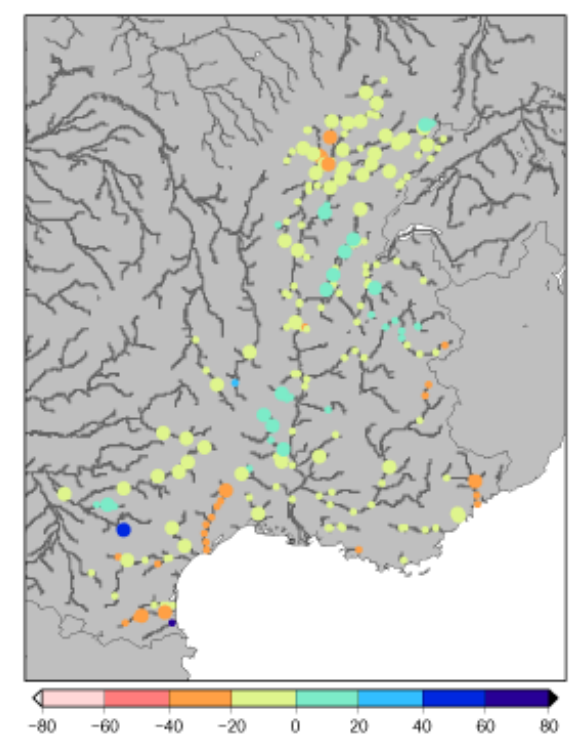

(b) WT

Fig. 11. Difference between the QMNA5 calculated with the two simulations forced by downscaling methods and the simulation forced by SAFRAN/F (in \%) for the period 1970-1999.

efficiencies (Habets et al., 2008; Quintana Seguí et al., 2009).

2. Both downscaling techniques produce an underestimation of the QJXA10 for most of the stations, with the most important differences being located over the relief of the Cévennes, where many small scale convective events take place. WT underestimations can reach $-80 \%$.

3. Both methods also cause an underestimation of QMNA5, but the differences between the methods are not as significant as in the previous case. It was expected, from Fig. 5 that the differences would be greater, as the number of consecutive dry days was better estimated by WT than by QM. Therefore, we could expect that the QMNA5 simulated with WT was closer to the reference than those obtained with QM. The processes leading to these droughts are slow, as they are related to fluxes of water within the soil, which might explain the similarity of the results.

From these results, it can be seen that the ability of a downscaling method to reproduce the indices of extreme precipitation does not give enough information about the ability of the method to reproduce the extremes of river flow. This is especially true for the low flows. In fact, the ability of the methods to reproduce other variables not analysed in this study, such as temperature, might be the key to understanding these differences. Quintana Seguí et al. (2010) showed that WT is approximately $1^{\circ} \mathrm{C}$ warmer than $\mathrm{QM}$.

\subsubsection{Spatial comparison of the simulations: 2035-2064}

Regarding the future climate, first we analysed what anomalies were expected for each station and method. Each of the plots of Fig. 12 compares the past and future periods simulated using a specific method. Concerning QJXA10, the anomalies of AN are not as important as those of QM and WT, especially for the stations with greater values. This is due to the fact that AN cannot produce changes of precipitation other than those related to the mean. Comparing WT and QM, in WT there are strong positive anomalies all over the spectrum, whereas QM tends to concentrate the largest anomalies on the gauging stations with higher QJXA10, which can be either positive or negative, in some cases. The amplitudes of the anomalies of QMNA5 are much smaller than those of QJXA10, but they are mainly negative. These rivers, many of which already have very low flows in summer, will have even lower flows.

Afterwards, we analysed the spatial distribution of these changes. First, we studied how frequently the river flows corresponding to past QJXA10 and QMNA5 would become in the future.

For high flows (Fig. 13), in the southern part of the domain, the three methods agree on an increase in the frequency of events. The high flow that had a return period of 10 years at the end of the 20th century will have a return period of less than ten years in the middle of the 21 st century. This is especially true for the Cévennes region, where the new return periods can be shorter than $2 \mathrm{yr}$. This area is already prone to catastrophic flash floods. On the contrary, in the northern 


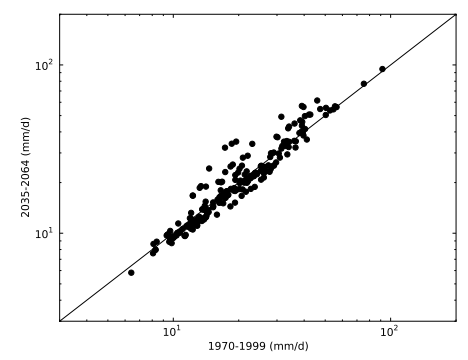

(a) AN QJXA10

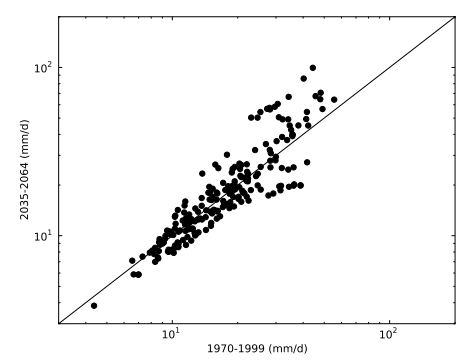

(c) QM QJXA10

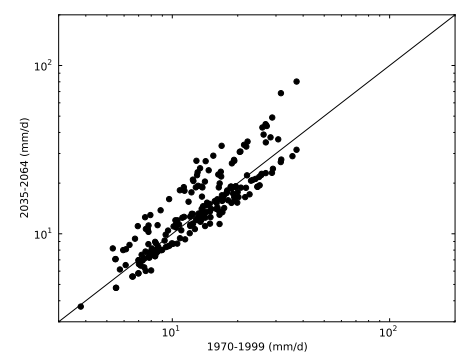

(e) WT QJXA10

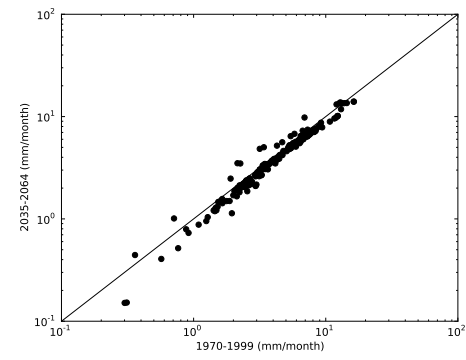

(b) AN QMNA5

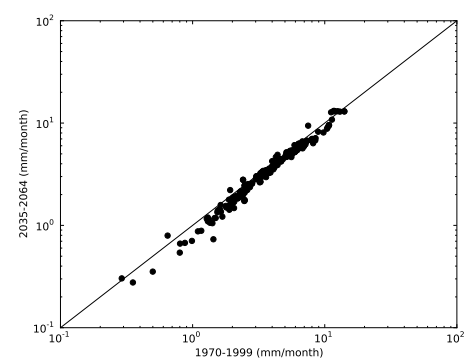

(d) QM QMNA5

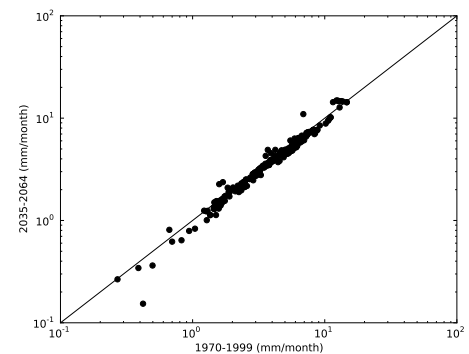

(f) WT QMNA5

Fig. 12. Comparison of the past and future simulated QJXA10 and QMNA5 for the individual gauging stations.

half of the domain, the frequency of high flows will diminish in most of the analysed basins. QM and WT present differences in the localisation of the changes, correlated with the spatial differences in their extreme rainfall. As expected, the AN changes are less severe, but the modification of the extremes estimated by AN shows similar patterns to those of QM and WT, which is surprising.

Figure 14 shows the changes in the frequency QMNA5. QM presents the most pessimistic scenario. This is coherent with the reduction of minimum precipitation during the summer (PDJJA) presented in Fig. 7. In this case, the return period of this flow will be between 2 and $4 \mathrm{yr}$, instead of 5, for most stations. WT and AN are less pessimistic, even though they also present an increase in the frequency for most stations. The northern part of the domain, the Saône, is the place where there is more agreement (in contrast to high flows). There the return period will decrease, but in general will remain higher than 2 yr. On the contrary, the differences are more important for the southern part of the domain, the most Mediterranean area.

Both figures also show that the changes in frequency for the stations where the NSE is not very good or there was not enough observed data to evaluate the NSE (small dots) are very similar to those of close "good" stations. When dealing with anomalies, some systematic errors of the simulation cancel out. Therefore, the results on the anomalies are more robust than those on the absolute values, providing confidence in the methodology used in this study.

The other analysis carried out for future periods is complementary to the previous one. In this case, the anomaly of QJXA10 and QMNA5 was studied, instead of the change in the return period. It is worth noting that the figures show the same patterns, but the amplitudes of the changes are less emphasised when comparing anomalies in percentage. 


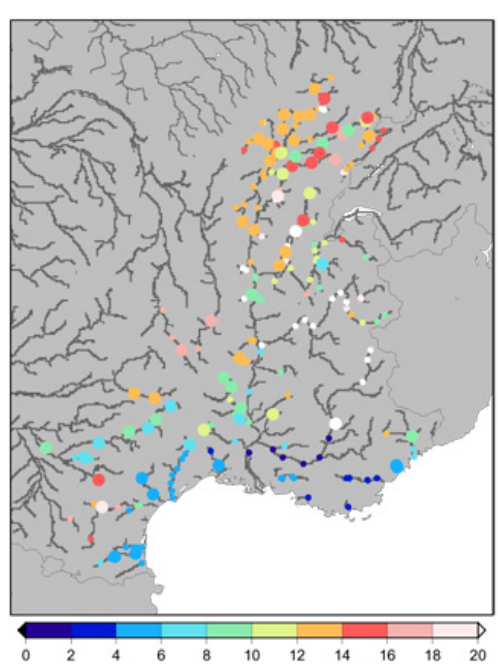

(a) $\mathrm{AN}$

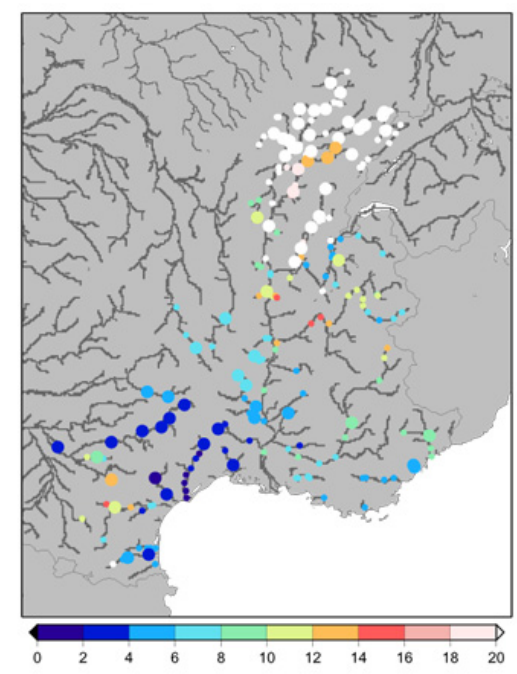

(b) QM

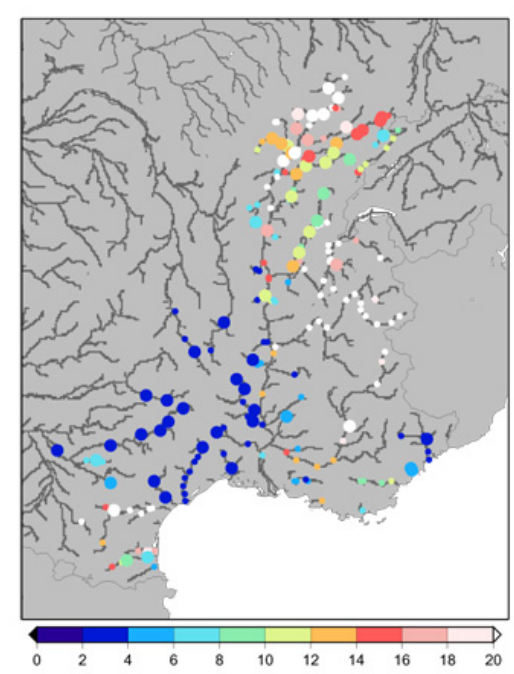

(c) WT

Fig. 13. Return period in years, calculated for 2035-2064, of the discharge corresponding to the QJXA10 of 1970-1999. Values smaller than 10 indicate a decrease of the return period.

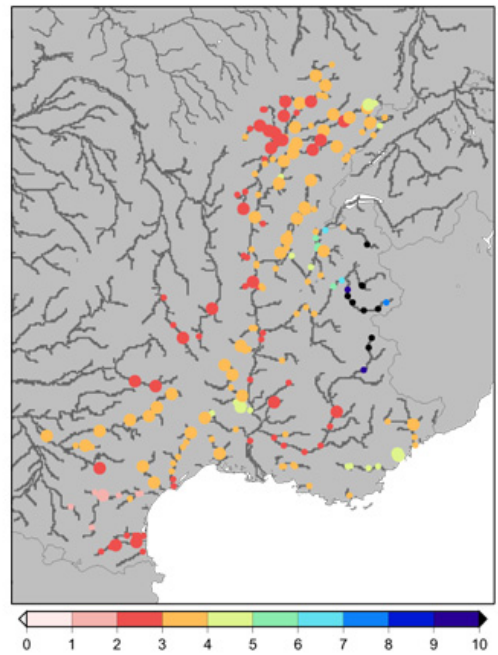

(a) AN

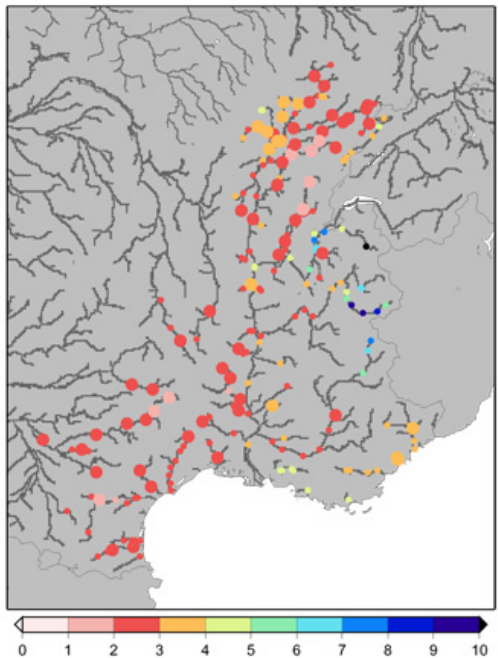

(b) QM

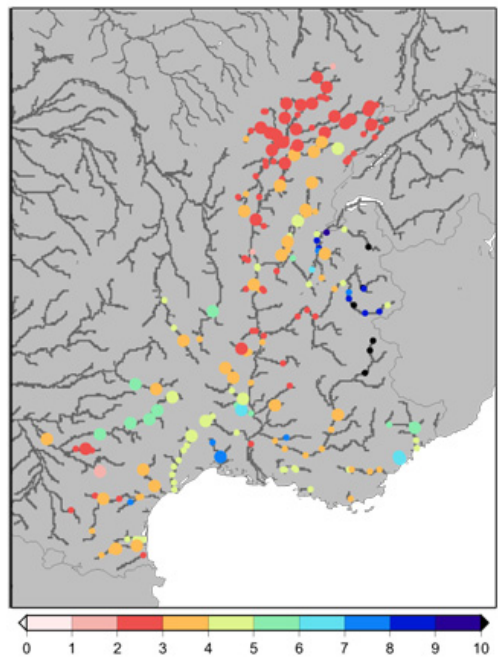

(c) WT

Fig. 14. Return period in years calculated for 2035-2064 of the discharge corresponding to the QMNA5 of 1970-1999. Values smaller than 5 indicate a decrease of the return period.

According to QM and WT (Fig. 15), the increase of the high flow with a return period of $10 \mathrm{yr}$ (QJXA10) will be higher than $60 \%$ for many stations close to the Cévennes. For some of them the anomaly will be even higher, beyond $100 \%$. The differences in location between QM and WT persist. In the northern part of the domain, the methods agree on a decrease of QJXA10 between 0 and $-20 \%$. AN estimates modifications of the extremes in the same order of magnitude, but the localisation of the changes is not the same. To be specific, the larger increase of the QJXA10 occurs in the western part of the Rhône river and not in the Cévennes as is the case with the other two downscaling methods.

Regarding QMNA5 (Fig. 16) there will be a reduction between 0 and $20 \%$ for most of the stations. According to WT, QMNA5 might increase on some of the stations of the southeastern part of the domain. But there are still significant differences between methods, due to the differences in the anomalies of the dry extremes of precipitation. 


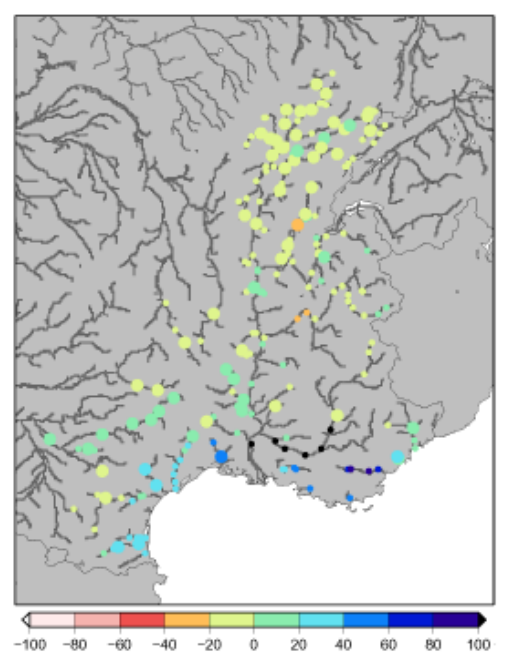

(a) $\mathrm{AN}$

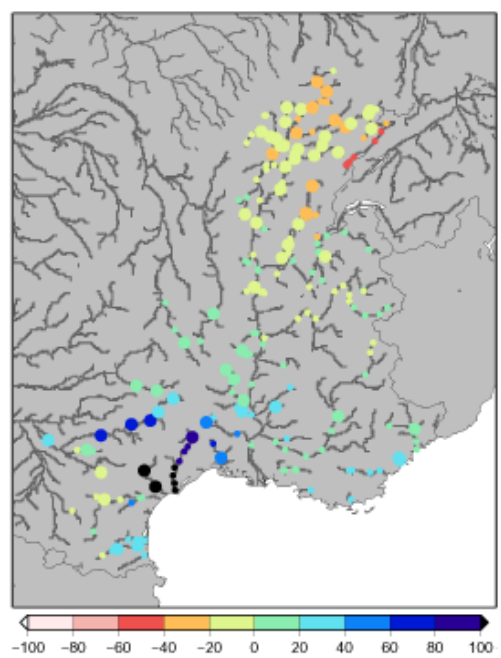

(b) QM

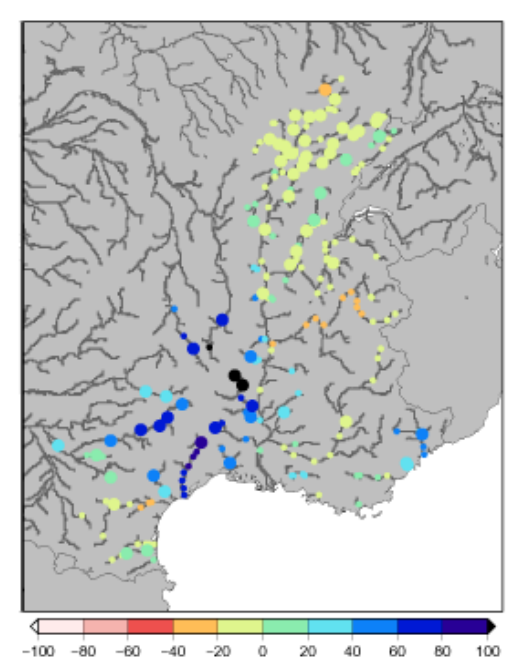

(c) WT

Fig. 15. Anomalies (2035-2064 vs. 1970-2099) of QJXA10 (in \%).

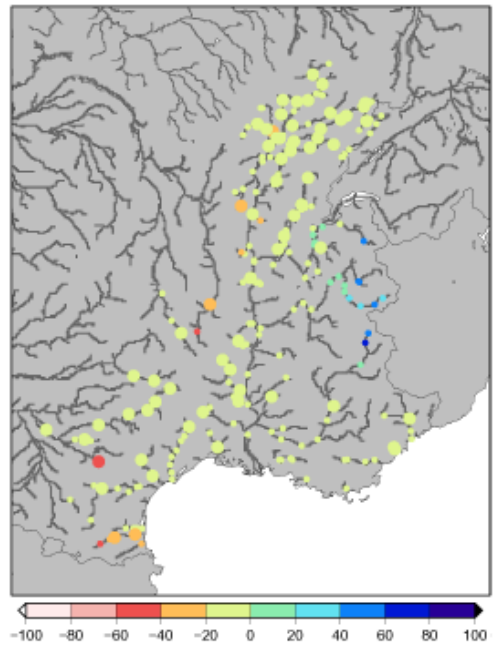

(a) $\mathrm{AN}$

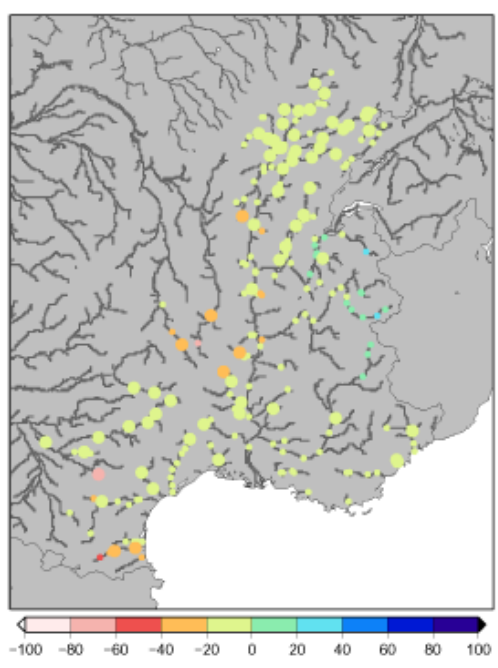

(b) QM

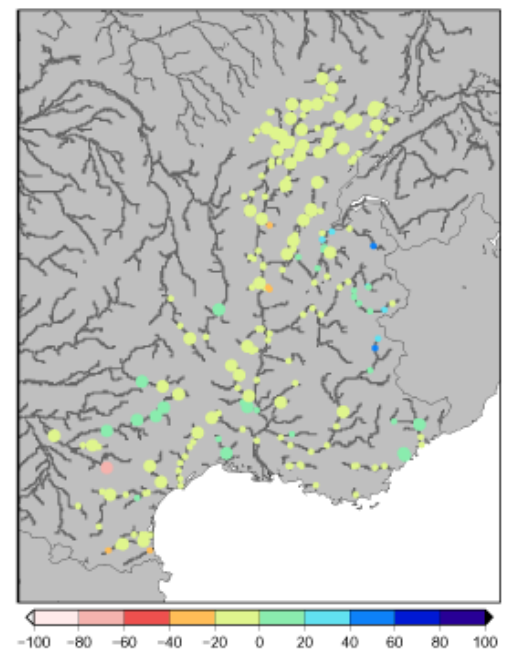

(c) WT

Fig. 16. Anomalies (2035-2064 vs. 1970-2099) of QMNA5 (in \%).

Once more, the anomalies for the stations where the model does not perform well are very similar to those of the stations where the model simulates well. Therefore, we are more confident the methodology is robust enough to study the anomalies in the magnitudes of the extremes.

\section{Discussion and conclusion}

This study compared how three different statistical downscaling and unbiasing techniques reproduce the high and low extremes of precipitation and the consequent river flows, as simulated by the SIM model, for past and future climate.
It was found that, except in the case of the simple AN, the methods were able to reproduce the observed extremes of precipitation, improving the performance of the RCM by providing information from the local scale, as already stated by Fowler et al. (2007) or Déqué (2007). The only exceptions are the difficulties that QM has in reproducing the longest drier period and the difficulties that both methods have with the area of the Cévennes, where the extremes of precipitation tend to be convective, especially in the case of WT.

How the hydrological model SIM is able to reproduce the high and low extremes of river flow when it is forced by SAFRAN/F (pseudo-observed atmospheric forcing) and the downscaled data was also studied. It was shown that the 
model reproduces the high extremes of flow reasonably well, but it has some difficulties regarding low flows.

Regarding the downscaling methods, both have lower scores than SAFRAN/F, as expected, but the scores of WT were surprisingly poor. This leads to an important result of this study: the skill of the downscaling methods in reproducing the extremes of precipitation is not transferred in a straightforward manner to the simulation of the extremes of river flow, as the hydrological model may amplify the differences and other atmospheric variables may play an important role.

Some of the poor performances of WT might be due to this specific application of the method (which was developed to reproduce the climate of the whole of France, not only the Mediterranean region), but it is certain that this method has some intrinsic difficulties in reproducing the convective events that are so important in this region. This is partly due to the fact that these local events are not fully explained by the large scale predictor, as their causes are mainly to be found on the meso scale. Quintana Seguí et al. (2010) showed that WT was, on average, drier and warmer, even in the present day. Thus, the soil moisture might be too dry at the beginning of the flash flood events. In fact, the initial conditions of soil moisture have an impact on the intensity of the hydrological response of high precipitation events in the Cévennes (Chancibault et al., 2006) and in Europe in general (Marchi et al., 2010). Regarding the comparison with observations, it must be taken into account that the comparison was carried out using non- naturalised series of observations, which is a limitation of the study. Therefore, they are affected by river management, which the model is not able to simulate. However, human influence is not the only cause of the bad performance in some cases.

Another result of the study is that the AN method is, as expected, the least capable regarding the reproduction of changes in the occurrence of the extremes. The extremes of precipitation of AN are very different to those estimated by the two other downscaling methods. Indeed, the largest values of PQ95 are expected to decrease with AN in most of the domain, while they increase according to the other two methods. However, the evolution of the extremes of river flow estimated using AN is fairly comparable to that obtained with the other more sophisticated downscaling methods. Such a result was not expected. In fact, Prudhomme et al. (2002) showed how the modification of wet spells has an impact on the simulation of floods, and by construction, the AN method is not able to modify wet spells. Thus, this result is surprising. It might be due to the large increase of the precipitations in winter by AN (Quintana Seguí et al., 2010), which may compensate for the fact that the precipitation regime is not modified. From these results, it can be said that AN is more robust than was expected a priori, even though it is not recommended to use it to study the extremes.

Studying the changes of the extremes in a future period, we saw that the methodology produces similar results for both the stations that the model simulates well (according to NSE) and the rest. This is a sign of robustness. In fact, it means that the systematic errors of the model partially cancel out when working with the anomalies. This assumption, which is very common in impact studies, also holds for the extremes of river flow.

There are differences in the exact location of the changes in the extremes. This is coherent with the results from Quintana Seguí et al. (2010), who studied the yearly and seasonal means. These spatial differences cause important differences between methods when looking at a specific gauging station, therefore the downscaling techniques introduce an uncertainty that must be taken into account. However, when looking at the whole pattern of change, the simulated futures look similar. For example, from this study (taking into account that only one RCM simulation was used), it is clear that the extremes of river flow will increase strongly in the Cévennes. However, it is not possible to say exactly how large the change will be for a specific basin.

This study does not evaluate all the uncertainties that affect the final results: emissions scenario, GCM, RCM, hydrological model, uncertainties related to the calculation of the return periods and significativity of the anomalies. In spite of this limitation, which should be solved in future studies, it is worth it to take into account its evaluation of the impacts of climate change on the extremes of precipitation and river flow. The study showed that, in the near future (2035-2064), monthly low flows are expected to diminish almost everywhere in the region (between 0 and $-20 \%$ ) and that the high flows will increase considerably, by more than $100 \%$ in some stations in the Southwest of the area of study, a region already prone to catastrophic flash-floods. In fact, the $10 \mathrm{yr}$ return flood may happen every two years or even more often for many stations. These results, which are coherent with the ones obtained by Dankers and Feyen (2009) for the Rhône basin (they found an increase of the 100-yr return period flood using several RCM with one hydrological model and no downscaling method), present a challenge for water and risk management, as the period studied is quite close in time, compared to the lifespan of many hydraulic infrastructures.

\section{Appendix A}

\section{Gauging stations used for this study}

Table A1 contains a list of the gauging stations used in this study, including its code, name, size and NSE score of the hydrological model forced by SAFRAN/F. 
Table A1. Gauging stations used to validate the simulated river discharge. The stations are divided into two blocks, according to the model's NSE.

\begin{tabular}{|c|c|c|c|c|}
\hline Code & Basin & Station & Surface $\left(\mathrm{km}^{2}\right)$ & NSE \\
\hline \multicolumn{5}{|c|}{$\mathrm{NSE}>0.5$} \\
\hline V2202010 & Ain & Marigny & 746 & 0.58 \\
\hline V2322010 & Ain & Cernon & 1230 & 0.65 \\
\hline V2712010 & Ain & Pont d'ain & 2871 & 0.57 \\
\hline V2942010 & Ain & Chazey sur Ain & 3773 & 0.63 \\
\hline U2354010 & Allan & Courcelles les Mont & 1175 & 0.76 \\
\hline K2210810 & Allier & Monistrol d'allier & 1344 & 0.71 \\
\hline V5004010 & Ardeche & Pont de Labeaume & 342 & 0.79 \\
\hline V5014010 & Ardeche & Vogue & 626 & 0.8 \\
\hline V5064010 & Ardeche & St Martin & 2288 & 0.86 \\
\hline Y1232010 & Aude & Carcassonne & 1836 & 0.7 \\
\hline U4624010 & Azergues & Chatillon & 376 & 0.56 \\
\hline V5474010 & Ceze & La Roque & 1074 & 0.67 \\
\hline U2425260 & Cusancin & Baume les Dames & 374 & 0.61 \\
\hline O4774010 & Dadou & Montdragon & 604 & 0.64 \\
\hline U2215020 & Dessoubre & St Hippolyte & 564 & 0.57 \\
\hline U2402010 & Doubs & Voujeaucourt & 3532 & 0.66 \\
\hline U2412020 & Doubs & Branne & 3850 & 0.64 \\
\hline U2512010 & Doubs & Besancon & 4462 & 0.77 \\
\hline U2542010 & Doubs & Rochefort & 4953 & 0.79 \\
\hline U2722010 & Doubs & Neublans & 7273 & 0.87 \\
\hline X1130010 & Durance & Oraison & 6778 & 0.62 \\
\hline V4144010 & Eyrieux & Beauvene & 473 & 0.65 \\
\hline V1264010 & Fier & Vallieres & 1315 & 0.65 \\
\hline V7124010 & Gardon de Mialet & Generargues & 268 & 0.74 \\
\hline U3214010 & Grosne & Jalogny & 344 & 0.68 \\
\hline Y2102010 & Herault & Laroque & 818 & 0.7 \\
\hline U0474010 & Lanterne & Fleurey & 1034 & 0.66 \\
\hline K0550010 & Loire & Bas en Basset & 3298 & 0.67 \\
\hline O7101510 & Lot & Banassac & 1134 & 0.7 \\
\hline O7131510 & Lot & Lassouts & 1640 & 0.74 \\
\hline U2604030 & Loue & Vuillafans & 379 & 0.55 \\
\hline U2624010 & Loue & Chenecey Buillon & 1135 & 0.74 \\
\hline U2634010 & Loue & Champagne & 1353 & 0.78 \\
\hline U2654010 & Loue & Parcey & 1721 & 0.82 \\
\hline U1235020 & Norges & Genlis & 263 & 0.5 \\
\hline U1054010 & Ognon & Beaumotte Aubertans & 1337 & 0.66 \\
\hline U1084010 & Ognon & Pesmes & 2186 & 0.62 \\
\hline Y2554010 & Orb & Vieussan & 939 & 0.75 \\
\hline Y2584010 & Orb & Beziers & 1377 & 0.77 \\
\hline U1324010 & Ouche & Plombieres & 660 & 0.56 \\
\hline U1334020 & Ouche & Crimolois & 891 & 0.58 \\
\hline U1334010 & Ouche & Trouhans & 928 & 0.63 \\
\hline V6052010 & Ouveze & Vaison la Romaine & 599 & 0.51 \\
\hline V3130010 & Rhone & Givors & 51431 & 0.6 \\
\hline U0724010 & Salon & Denevre & 392 & 0.72 \\
\hline U0230010 & Saone & Cendrecourt & 1177 & 0.68 \\
\hline U0610010 & Saone & Ray & 4010 & 0.77 \\
\hline U1420010 & Saone & Lechatelet & 11867 & 0.83 \\
\hline U4300010 & Saone & Macon & 26336 & 0.83 \\
\hline U3424010 & Seille & St Usuge & 869 & 0.76 \\
\hline Y5534030 & Siagne & Pegomas & 514 & 0.74 \\
\hline Y5534040 & Siagne & Mandelieu & 521 & 0.67 \\
\hline
\end{tabular}


Table A1. Continued.

\begin{tabular}{|c|c|c|c|c|}
\hline O3121010 & Tarn & Montbrun & 662 & 0.82 \\
\hline O3141010 & Tarn & St Pierre & 1028 & 0.79 \\
\hline O3401010 & Tarn & Millau & 2164 & 0.79 \\
\hline O3471010 & Tarn & St Victor & 2799 & 0.72 \\
\hline O3841010 & Tarn & Marsal & 4643 & 0.82 \\
\hline O4931010 & Tarn & Villemur & 9308 & 0.83 \\
\hline Y0464030 & Tet & Rodes & 1019 & 0.59 \\
\hline Y0474030 & Tet & Perpignan & 1399 & 0.64 \\
\hline O4394010 & Thore & Labruguiere & 509 & 0.68 \\
\hline U1244030 & Tille aux Maillys & Ille aux Maillys & 1295 & 0.65 \\
\hline V2624010 & Valouse & Thoirette & 283 & 0.67 \\
\hline Y6432010 & Var & Malaussene & 1845 & 0.55 \\
\hline Y3464010 & Vidourle & Marsillargues & 794 & 0.77 \\
\hline U0924010 & Vingeanne & St Maurice & 432 & 0.52 \\
\hline U0924020 & Vingeanne & Oisilly & 614 & 0.7 \\
\hline \multicolumn{5}{|c|}{$\mathrm{NSE}<0.5$} \\
\hline U0234010 & Amance & Raincourt & 454 & 0.23 \\
\hline Y4122010 & Arc & Aix en Provence & 578 & 0.03 \\
\hline W1024010 & Arc & Bramans & 638 & -15.32 \\
\hline W1034010 & Arc & St Michel & 954 & -4.43 \\
\hline Y5112010 & Argens & Carces & 1174 & 0.03 \\
\hline Y5312010 & Argens & Roquebrune & 2524 & 0.2 \\
\hline Y5202010 & Argens & Arcs & 1706 & -0.02 \\
\hline V0222010 & Arve & Arthaz & 1848 & 0.37 \\
\hline U4644010 & Azergues & Lozanne & 865 & 0.48 \\
\hline V2444010 & Bienne & Chassal & 560 & 0.48 \\
\hline V2444020 & Bienne & Jeurre & 690 & 0.49 \\
\hline U2022010 & Doubs & La Cluse et Mijoux & 425 & -1.16 \\
\hline U2102010 & Doubs & Ville Du Pont & 649 & -0.82 \\
\hline U2122010 & Doubs & Goumois & 1169 & 0.03 \\
\hline U2142010 & Doubs & Glere & 1309 & 0.19 \\
\hline U2222010 & Doubs & Mathay & 2168 & 0.39 \\
\hline V3724010 & Doux & Colombier le Vieux & 478 & 0.25 \\
\hline X0100010 & Durance & Briancon & 562 & -0.36 \\
\hline X0310010 & Durance & Embrun & 2326 & 0.26 \\
\hline X3000010 & Durance & St Paul les Duran & 11757 & -0.22 \\
\hline Y4624010 & Gapeau & Hyeres & 540 & 0.42 \\
\hline V3224010 & Gere & Pont l'eveque & 383 & -20.6 \\
\hline V3114010 & Gier & Rive de Gier & 357 & 0.36 \\
\hline V3124010 & Gier & Givors & 430 & 0.47 \\
\hline U3225010 & Guye & Sigy le Chatel & 286 & 0.16 \\
\hline W0300010 & Isere & Aigueblanche & 1588 & -4.3 \\
\hline W1100010 & Isere & Chamousset & 4713 & -2.49 \\
\hline W1410010 & Isere & Grenoble & 5782 & -2.11 \\
\hline W3200010 & Isere & St Gervais & 10017 & -1.35 \\
\hline W3540010 & Isere & Beaumont Monteux & 11880 & -1.19 \\
\hline U1074010 & Ognon & Chevigney & 1884 & 0.38 \\
\hline V1000010 & Rhone & Pougny & 10430 & -2.57 \\
\hline V1020010 & Rhone & Injoux Genissiat & 11032 & -1.95 \\
\hline V1630010 & Rhone & Sault Brenaz & 15441 & -0.61 \\
\hline V3000010 & Rhone & Caluire et Cuire & 20780 & -0.01 \\
\hline V7200010 & Rhone & Beaucaire & 96412 & 0.32 \\
\hline V2814030 & Suran & Pont d'ain & 346 & 0.48 \\
\hline Y0444010 & Tet & Marquixanes & 947 & 0.22 \\
\hline U1224020 & Tille & Cessey & 902 & 0.04 \\
\hline Y6234010 & Tinee & La Tour & 705 & -0.12 \\
\hline Y6042010 & Var & Entrevaux & 679 & -0.45 \\
\hline
\end{tabular}


Acknowledgements. The authors acknowledge and thank Julien Boé and Aurélien Ribes, upon whose work this article was built, Étienne Leblois and Cédric David, for their valuable insights, the anonymous reviewers, for their comments and suggestions which improved the quality of the final version of the manuscript, and María del Carmen González, for her constant support.

Edited by: P. Lionello

Reviewed by: three anonymous referees

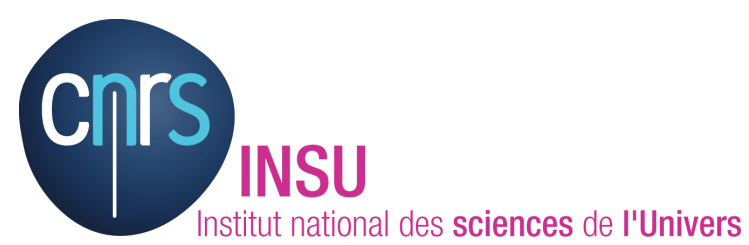

The publication of this article is financed by CNRS-INSU.

\section{References}

Beniston, M., Stephenson, D. B., Christensen, O. B., Ferro, C. A. T., Frei, C., Goyette, S., Halsnaes, K., Holt, T., Jylhä, K., Koffi, B., Palutikof, J., Schöll, R., Semmler, T., and Woth, K.: Future extreme events in European climate: an exploration of regional climate model projections, Climatic Change, 81, 71-95, doi:10.1007/s10584-006-9226-z, 2007.

Boberg, F., Berg, P., Thejll, P., Gutowski, W. J., and Christensen, J. H.: Improved confidence in climate change projections of precipitation further evaluated using daily statistics from ENSEMBLES models, Clim. Dynam., doi:10.1007/s00382-009-0683-8, 2009.

Boé, J.: Changement global et cycle hydrologique : Une étude de régionalisation sur la France, Phd thesis, Université de Toulouse (Toulouse III - Paul Sabatier), available at: http://www.cerfacs. fr/globc/publication/thesis/2007/these_boe.pdf, 2007.

Boé, J. and Terray, L.: A Weather-Type Approach to Analyzing Winter Precipitation in France: Twentieth-Century Trends and the Role of Anthropogenic Forcing, J. Clim., 21, 3118, doi:10.1175/2007JCLI1796.1, 2008.

Boé, J., Terray, L., Habets, F., and Martin, E.: A simple statistical-dynamical downscaling scheme based on weather types and conditional resampling, J. Geophys. Res., 111, 1-20, doi:10.1029/2005JD006889, 2006.

Boé, J., Terray, L., Martin, E., and Habets, F.: Projected changes in components of the hydrological cycle in French river basins during the 21 st century, Water Resour. Res., 45, 1-49, doi:10.1029/2008WR007437, 2009.

Boone, A., Calvet, J. C., and Noilhan, J.: Inclusion of a Third Soil Layer in a Land Surface Scheme Using the Force-Restore Method, J. Appl. Meteorol., 38, 1611-1630, 1999.

Caballero, Y., Voirin-Morel, S., Habets, F., Noilhan, J., LeMoigne, P., Lehenaff, A., and Boone, A.: Hydrological sensitivity of the Adour-Garonne river basin to climate change, Water Resour. Res., 43, W07448, doi:10.1029/2005WR0041922007, 2007.

Chancibault, K., Anquetin, S., Ducrocq, V., and Saulnier, G.-M.: Hydrological evaluation of high-resolution precipitation forecasts of the Gard flash-flood event (8-9 September 2002), Q.
J. Roy. Meteor. Soc., 132, 1091-1117, doi:10.1256/qj.04.164, 2006.

Cunderlik, J. M. and Simonovic, S. P.: Hydrological extremes in a southwestern Ontario river basin under future climate conditions/Extrêmes hydrologiques dans un basin versant du sud-ouest de l'Ontario sous conditions climatiques futures, Hydrolog. Sci. J., 50, 631-654, doi:10.1623/hysj.2005.50.4.631, 2005.

Dankers, R. and Feyen, L.: Flood hazard in Europe in an ensemble of regional climate scenarios, J. Geophys. Res., 114, D16108, doi:10.1029/2008JD011523, 2009.

Decharme, B., Douville, H., Boone, A., Habets, F., and Noilhan, J.: Impact of an Exponential Profile of saturated Hydraulic Conductivity within the ISBA LSM: Simulations over the Rhône Basin, J. Hydrometeorol., 7, 61-80, 2006.

Delrieu, G., Ducrocq, V., Gaume, E., Nicol, J., Payrastre, O., Yates, E., Kirstetter, P.-E., Andrieu, H., Ayral, P.-A., Bouvier, C., Creutin, J.-D., Livet, M., Anquetin, S., Lang, M., Neppel, L., Obled, C., Du-Châtelet, J. P., Saulnier, G.-M., Walpersdorf, A., and Wobrock, W.: The Catastrophic Flash-Flood Event of 8-9 September 2002 in the Gard Region, France: A First Case Study for the Cévennes-Vivarais Mediterranean Hydrometeorological Observatory, J. Hydrometeorol., 6, 34-52, doi:10.1175/JHM-400.1, 2005.

Déqué, M.: Frequency of precipitation and temperature extremes over France in an anthropogenic scenario: Model results and statistical correction according to observed values, Global Planet. Change, 57, 16-26, doi:10.1016/j.gloplacha.2006.11.030, 2007.

Dubrovský, M., Buchtele, J., and Žalud, Z.: High-Frequency and Low-Frequency Variability in Stochastic Daily Weather Generator and Its Effect on Agricultural and Hydrologic Modelling, Climatic Change, 63, 145-179, doi:10.1023/B:CLIM.0000018504.99914.60, 2004.

Ducrocq, V., Ricard, D., Lafore, J.-P., and Orain, F.: Storm-Scale Numerical Rainfall Prediction for Five Precipitating Events over France: On the Importance of the Initial Humidity Field, Weather and Forecasting, 17, 1236-1256, doi:10.1175/15200434(2002)017;1236:SSNRPF;2.0.CO;2, 2002.

Durand, Y., Brun, E., Merindol, L., Guyomarc'h, G., Lesaffre, B., and Martin, E.: A meteorological estimation of relevant parameters for snow models, Ann. Glaciol., 18, 65-71, 1993.

Fowler, H. J., Blenkinsop, S., and Tebaldi, C.: Linking climate change modelling to impacts studies: recent advances in downscaling techniques for hydrological modelling, Int. J. Climatol., 27, 1547-1578, doi:10.1002/joc.1556, 2007.

Frei, C., Christensen, J. H., Déqué, M., Jacob, D., Jones, R. G., and Vidale, P. L.: Daily precipitation statistics in regional climate models: Evaluation and intercomparison for the European Alps, J. Geophys. Res., 108(D3), 4124, doi:10.1029/2002JD002287, 2003.

Frei, C., Schöll, R., Fukutome, S., Schmidli, J., and Vidale, P. L.: Future change of precipitation extremes in Europe: Intercomparison of scenarios from regional climate models, J. Geophys. Res., 111, D06105, doi:10.1029/2005JD005965, 2006.

Gibelin, A.-L. and Déqué, M.: Anthropogenic climate change over the Mediterranean region simulated by a global variable resolution model, Clim. Dynam., 20, 327-339, 2003.

Giorgi, F.: Simulation of Regional Climate Using a Limited Area Model Nested in a General Circulation Model, J. Climate, 3, 941-963, 1990. 
Goodess, C.: STAtistical and Regional dynamical Downscaling of EXtremes for European regions: STARDEX, available at: http: //www.the-eggs.org/data/eggs_06.pdf (last access: 3 April 2003), 2003.

Gutowski, W. J., Decker, S. G., Donavon, R. A., Pan, Z., Arritt, R. W., and Takle, E. S.: Temporal-Spatial Scales of Observed and Simulated Precipitation in Central US Climate, J. Climate, 16, 3841, doi:10.1175/15200442(2003)016;3841:TSOOAS $;$ 2.0.CO;2, 2003.

Habets, F., Boone, A., Champeaux, J. L., Etchevers, P., Franchistéguy, L., Leblois, E., Ledoux, E., Le Moigne, P., Martin, E., Morel, S., Noilhan, J., Quintana Seguí, P., Rousset-Regimbeau, F., and Viennot, P.: The SAFRAN-ISBA-MODCOU hydrometeorological model applied over France, J. Geophys. Res., 113, D06113, doi:10.1029/2007JD008548, 2008.

Ledoux, E., Girard, G., de Marsilly, G., and Deschenes, J.: Spatially distributed modeling: conceptual approach, coupling surface water and ground water., Kluwer Academic, Dordrecht, 435-454, 1989.

Lehner, B., Döll, P., Alcamo, J., Henrichs, T., and Kaspar, F.: Estimating the Impact of Global Change on Flood and Drought Risks in Europe: A Continental, Integrated Analysis, Climatic Change, 75, 273-299, doi:10.1007/s10584-006-6338-4, 2006.

Maraun, D., Wetterhall, F., Ireson, A. M., Chandler, R. E., Kendon, E. J., Widmann, M., Brienen, S., Rust, H. W., Sauter, T., Venema, V. K. C., Chun, K. P., Goodess, C. M., Jones, R. G., Onof, C., Vrac, M., Office, M., and Centre, H.: Precipitation downscaling under climate change. recent developments to bridge the gap between dynamical models and the end user, Rev. Geophys., 48, RG3003, doi:10.1029/2009RG000314, 2010.

Marchi, L., Borga, M., Preciso, E., and Gaume, E.: Characterisation of selected extreme flash floods in Europe and implications for flood risk management, J. Hydrol., 394, 118-133, doi:10.1016/j.jhydrol.2010.07.017, 2010.

Masson, V., Champeaux, J.-L., Chauvin, F., Meriguet, C., and Lacaze, R.: A Global Database of Land Surface Parameters at 1-km Resolution in Meteorological and Climate Models, J. Climate, 16, 1261-1282, 2003.

Nakicenovic, N. and Swart, R.: Emissions Scenarios, Tech. rep., IPCC, Geneva (Switzerland), available at: http://www.ipcc.ch/ ipccreports/sres/emission/ (last access: 23 November 2009), 2000.

Nash, J. and Sutcliffe, J.: River flow forecasting through conceptual models part I? A discussion of principles, J. Hydrol., 10, 282290, 1970.

Noilhan, J. and Mahfouf, J.: The ISBA land surface parameterisation scheme, Global Planet. Change, 13, 145-159, 1996.

Noilhan, J. and Planton, S.: A Simple Parameterization of Land Surface Processes for Meteorological Models, Mon. Weather Rev., 117, 536-549, 1989.

Pagé, C., Terray, L., and Boé, J.: Projections climatiques à échelle fine sur la France pour le 21ème siècle : les scénarii SCRATCH08., 2008.

Planton, S., Deque, M., Chauvin, F., and Terray, L.: Expected impacts of climate change on extreme climate events, Comptes Rendus Geosciences, 340, 564-574, doi:10.1016/j.crte.2008.07.009, 2008.

Prudhomme, C., Reynard, N., and Crooks, S.: Downscaling of global climate models for flood frequency analysis: where are we now?, Hydrol. Process., 16, 1137-1150, doi:10.1002/hyp.1054, http://doi.wiley.com/10.1002/hyp.1054, 2002.

Prudhomme, C., Jakob, D., and Svensson, C.: Uncertainty and climate change impact on the flood regime of small UK catchments, J. Hydrol., 277, 1-23, doi:10.1016/S0022-1694(03)00065-9, 2003.

Quintana-Seguí, P., Le Moigne, P., Durand, Y., Martin, E., Habets, F., Baillon, M., Canellas, C., Franchisteguy, L., and Morel, S.: Analysis of Near-Surface Atmospheric Variables: Validation of the SAFRAN Analysis over France, J. Appl. Meteorol. Clim., 47, 92-107, doi:10.1175/2007JAMC1636.1, 2008.

Quintana-Seguí, P., Martin, E., Habets, F., and Noilhan, J.: Improvement, calibration and validation of a distributed hydrological model over France, Hydrol. Earth Syst. Sci., 13, 163-181, doi:10.5194/hess-13-163-2009, 2009.

Quintana-Seguí, P., Ribes, A., Martin, E., Habets, F., and Boé, J.: Comparison of three downscaling methods in simulating the impact of climate change on the hydrology of Mediterranean basins, J. Hydrol., 383, 111-124, doi:10.1016/j.jhydrol.2009.09.050, 2010.

Raff, D. A., Pruitt, T., and Brekke, L. D.: A framework for assessing flood frequency based on climate projection information, Hydrol. Earth Syst. Sci., 13, 2119-2136, doi:10.5194/hess-132119-2009, 2009.

Ritter, B. and Geleyn, J. F.: A Comprehensive Radiation Scheme for Numerical Weather Prediction Models with Potential Applications in Climate Simulations, Mon. Weather Rev., 120, 303325, 1992.

Sauquet, E. and Leblois, E.: Discharge analysis and runoff mapping applied to the evaluation of model performance, Physics and Chemistry of the Earth, Part B: Hydrology, Oceans and Atmosphere, 26, 473-478, doi:10.1016/S1464-1909(01)00037-5, 2001.

Somot, S., Sevault, F., and Déqué, M.: Transient climate change scenario simulation of the Mediterranean Sea for the twenty-first century using a high-resolution ocean circulation model, Clim. Dynam., 27, 851-879, doi:10.1007/s00382-006-0167-z, 2006.

Somot, S., Sevault, F., Déqué, M., and Crepon, M.: 21st century climate change scenario for the Mediterranean using a coupled atmosphere-ocean regional climate model, Global Planet. Change, 63, 112-126, doi:10.1016/j.gloplacha.2007.10.003, 2008.

Strupczewski, W., Singh, V., and Feluch, W.: Non-stationary approach to at-site flood frequency modelling I, Maximum likelihood estimation, J. Hydrol., 248, 123-142, doi:10.1016/S00221694(01)00397-3, 2001.

Tisseuil, C., Vrac, M., Lek, S., and Wade, A. J.: Statistical downscaling of river flows, J. Hydrol., 385, 279-291, doi:10.1016/j.jhydrol.2010.02.030, 2010.

Trenberth, K. E., Dai, A., Rasmussen, R. M., and Parsons, D. B.: The Changing Character of Precipitation, Bull. Am. Meteorol. Soc., 84, 1205, doi:10.1175/BAMS-84-9-1205, 2003.

Vidal, J.-P., Martin, E., Franchistéguy, L., Baillon, M., and Soubeyroux, J.-M.: A 50-year high-resolution atmospheric reanalysis over France with the Safran system, Int. J. Climatol., in press, doi:10.1002/joc.2003, 2010.

von Storch, H.: Inconsistencies at the interface of climate impact studies and global climate research, Meteorol. Z., 4, 72-80, 1995. 
von Storch, H.: On the Use of "Inflation" in Statistical Downscaling, J. Climate, 12, 3505-3506, 1999.

Wilby, R. L., Charles, S. P., Zorita, E., Timbal, B., Whetton, P., and Mearns, L. O.: Guidelines for Use of Climate Scenarios Developed from Statistical Downscaling Methods, available at: http://www.ipcc-data.org/guidelines/dgm_no2_v1_ 09_2004.pdf (last access: 23 November 2009), 2004. 